\title{
LOS CARBUROS DE HIERRO COMO TESTIGOS DE LOS RITOS DE CREMACIÓN ENTRE LOS PUEBLOS PRERROMANOS DE LA PENÍNSULA IBÉRICA: ALGUNOS EJEMPLOS
}

\author{
IRON CARBIDES AS WITNESS TO CREMATION RITES AMONG PRE- \\ ROMAN PEOPLES OF THE IBERIAN PENINSULA: SOME EXAMPLES
}

\author{
ANTONIO JAVIER CRIADO MARTÍN* \\ ANTONIO JOSÉ CRIADO PORTAL* \\ MARÍA PILAR SAN NICOLÁS PEDRAZ** \\ LAURA GARCÍA SÁNCHEZ* \\ ALEJANDRO CRIADO MARTÍN*
}

\begin{abstract}
Resumen: El trabajo que se presenta trata sobre el estudio de unas microestructuras típicas que aparecen en el núcleo de piezas de acero incineradas con cadáveres entre los pueblos prerromanos de la península ibérica. A través de su análisis y la reproducción del proceso térmico y de envejecimiento que sufrieron estas piezas, con aceros modernos experimentales, de las mismas características, en laboratorio, podemos deducir datos como las temperaturas que se alcanzaban en estos ritos funerarios, las velocidades de enfriamiento de la pira, si las piezas de acero analizadas se quemaban junto al cadáver o se depositaban a posteriori junto a la urna cineraria sin que sufrieran exposición al fuego y los procesos termodinámicos que operaban en las piezas durante el rito y que dan como resultado estas estructuras.

Palabras claves: muestras arqueológicas de acero; ritos de cremación; estimación de temperatura; pueblos prerromanos; MEB; estructuras metalográficas; carburos de hierro.
\end{abstract}

\footnotetext{
* Grupo de Tecnología Mecánica y Arqueometalurgia, Departamento de Ciencia de los Materiales e Ingeniería Metalúrgica, Facultad de Ciencias Químicas, Universidad Complutense de Madrid. 28040, Madrid. Teléfono: 913944286.

** Departamento de Prehistoria y Arqueología, Facultad de Geografía e Historia, Universidad Nacional de Educación a Distancia. C/ Paseo Senda del Rey, 7, 4ª Planta. 28040, Madrid. Teléfono: 913986768.
}

\begin{abstract}
In the present work, typical microstructures appearing in the nucleus of archaeological steel which had suffered an incineration process were studied. Under study were different items (weapons, parts of clothing, etc.) burned together with dead bodies by pre-roman tribes inhabiting the Iberian Peninsula. The samples were analysed making use of optical and electron microscopy and and EDX spectrometry. The thermal and ageing processes were reproduced in the laboratory employing modern steel of similar composition. The results allowed to estimate the temperatures achieved during funerary rites as well as the cooling kinetics of the funeral pile. Further, it could be determined whether the pieces were burned together with the dead body or were later on deposited close to the urn. Finally, models of the thermodynamic processes which lead to the observed microstructures are proposed.

Key words: archaeological steel samples; cremation rites; temperature estimation; pre-roman tribes; SEM, metallographic structures; iron carbides.
\end{abstract}

\section{INTRODUCCIÓN}

\section{Justificación y objetivos}

El siguiente trabajo de investigación se enmarca dentro del campo de la Arqueometría y más concretamente en el de la Arqueometalurgia. Esta disciplina 
se ocupa del estudio de todo tipo de piezas arqueológicas de naturaleza metálica, desde sus características macroscópicas a sus estructuras microscópicas, aportando información tanto sobre los procesos de extracción del metal a partir del mineral, como de los niveles tecnológicos que alcanzaron los diferentes pueblos para transformar la materia prima en objetos útiles para diferentes usos.

Según Mohen (Mohen 1992: 9-18) la metalurgia es la manifestación prehistórica más avanzada en el conocimiento de los recursos naturales. La utilización directa de los materiales más accesibles, como ramas, piedra o hueso, va acompañada de transformaciones que modifican la forma de los soportes para darles la condición de objetos, útiles, armas y ornamentos. En un sistema de producción artificial, la materia prima natural se modifica en sus características físico-químicas: la cerámica y el metal representan estas novedades que a menudo aparecen al mismo tiempo que las primeras plantas cultivadas y los primeros animales domésticos. En este contexto, la metalurgia requiere técnicas más elaboradas en relación con las organizaciones económicas y sociedades específicas. ¿Qué esperaba el hombre prehistórico de estos nuevos materiales que eran los metales? En principio hay que señalar que de los 70 elementos metálicos naturales, los hombres prehistóricos y, en general, los de la Antigüedad, no utilizaron más que una decena, tratándose del oro, el electrón, la plata, el plomo, el cobre, el estaño, el antimonio, el platino, el arsénico, el mercurio, el hierro y el cinc. $\mathrm{Su}$ poder de atracción emanaba de algunas características comunes (Wheeler 1980: 99-126): su color, su brillo "metálico", su poder reflectante, su maleabilidad y colabilidad, su fácil reciclaje.

La importancia de los metales fue y sigue siendo tal, que la historia de la humanidad se divide en etapas asociadas a los metales. Así el filósofo y atomista romano Tito Lucrecio Caro (siglo I a. C.), en su obra titulada De rerum natura, divide la Historia de la Humanidad en tres etapas, cada una designada por un metal: el oro, el bronce y el hierro. De la misma forma, desde principios del siglo XIX, los arqueólogos daneses, entre los cuales cabe citar a Christian Thomsen Jürgensen como el más destacado (Jorge 1987: 1-15), elaboraron un sistema tripartito parecido al de Lucrecio. Denominaron a las diferentes etapas de la Historia de la $\mathrm{Hu}$ manidad de la siguiente forma: primero una Edad de la Piedra, al final de la cual aparecen el oro y el cobre; después una Edad del Bronce y, posteriormente, una Edad del Hierro. Esto se aplicó a la clasificación de las colecciones del nuevo Museo Nacional de Dinamarca de Copenhague. A partir de esos momentos se generalizó este sistema de clasificación. Queda claro que los metales son protagonistas de las diferentes etapas de la existencia de la humanidad. Su importancia fue tal que los reinos e imperios de la Antigüedad, se movían sobre objetivos socioeconómicos, políticos y militares basados en los diferentes metales: su control, su extracción y fabricación, los circuitos económicos, el armamento, los útiles, las monedas, etc.

Así los metales y aleaciones son auténticos testigos y vectores de información privilegiados para el conocimiento de hechos acaecidos en tiempos prehistóricos e históricos, y herramientas científicas irrefutables e indispensables para el arqueólogo e historiador en la construcción razonada de la Historia. La Arqueometalurgia es la "Arqueometría del Metal", tratándose de una ciencia joven pero con una contrastada experiencia. Los trabajos de laboratorio son ya clásicos en el estudio de la Arqueometalurgia o Metalurgia Antigua. Su avance es imparable y se refuerza cada vez más, ya que las hipótesis son contrastadas experimentalmente y los métodos de análisis y estudio, posibilitan la comparación científica de los resultados. La síntesis arqueometalúrgica debe hacerse teniendo en cuenta multitud de datos. Éstos se reflejan finalmente en una interpretación de la Historia de una manera más objetiva y enriquecedora de los hechos ocurridos a los seres humanos desde la más remota Antigüedad.

Afirma Criado (Criado 2000: 26; 2000: 149-160; 2003: 231-260; 2004: 107-117; 2004: 107-115; 2005: 550-591) que como en todas las ciencias experimentales también en la Arqueometalurgia hay dos maneras de actuación, una más tecnológica y otra más científica. La primera se limita a realizar análisis químicos, identificación de derrames, escorias, lingotes, moldes, estudios de minería, metalurgia extractiva y procesos de fabricación de metales y aleciones, moldeo, forja, etc. En cambio, la más científica, investiga vectores para poder interpretar a través de análisis químicos, metalográficos y mecánicos, una información más allá de la tecnológica. Éstos deben servir como testigos inequívocos y eficaces de lo que ocurrió a su alrededor, aportando una información que por la vía tecnológica no es posible, ya que los análisis y la observación directa no puede extraer una información tan valiosa ni tan sutil.

La investigación que llevamos a cabo en este trabajo pretende obtener un vector de probada fiabilidad para asegurar si una pieza de acero ha sufrido un proceso de incineración $\mathrm{u}$ otros tratamientos térmicos como incendios, envejecimiento estructural con el tiempo, etc. Todo esto debe ser aplicable a artefactos 
de acero contextualizados o no, con la única y mínima exigencia de que queden algunos miligramos del metal sin corrosión. Para ello tratamos de ver estructuras metalográficas específicas de cada situación y, después de interpretarlos, intentamos su reproducción en el laboratorio para validar las hipótesis supuestas después de la observación de esas estructuras peculiares y características.

De esta manera en el caso que afrontamos aquí se analizan una serie de piezas de hierro y acero, con funcionalidades diversas, cubriendo una cronología desde el siglo V a. C. al siglo II a. C. Abarcan un amplio ámbito geográfico involucrando a la cultura ibérica y celtibérica, siendo las piezas estudiadas las que a continuación se enumeran: pilum ibérico (Cerro Muriano, Córdoba), hebilla de placas de defensa (Villanueva de Teba, Burgos), tachuela (Villanueva de Teba, Burgos), falcata ibérica (Museo Armería Vitoria-Gasteiz).

Antes de entrar en materia es indispensable afirmar que el hierro puro tiene su punto de fusión en los $1540^{\circ} \mathrm{C}$, temperatura difícil de lograr en los hornos de esta época, que no alcanzaban temperaturas superiores a $\operatorname{los} 1200^{\circ} \mathrm{C}$, suficientes para conseguir en estado líquido metales como el cobre o el bronce. El hierro se obtenía mediante una lupia o pella esponjosa sólida contaminada con carbón vegetal, fundentes, etc., por reducción en estado sólido de la mena metálica, mediante este carbón vegetal y los fundentes adecuados. La entrada era forzada mediante la acción de un fuelle. Tras un calentamiento $\left(1100^{\circ}\right.$ a $\left.1200^{\circ} \mathrm{C}\right)$, la escoria fluía hacia el fondo del horno, dejando la pella esponjosa a la altura de las toberas de soplado. Esta masa era luego martilleada, en caliente, provocando la concentración del metal a la vez que se retiraba la escoria.

Las composiciones medias de este hierro esponjoso, junto con las encontradas en las piezas arqueológicas por el grupo de investigación, fueron las que determinaron que los aceros que se utilizarían para el presente trabajo fuesen los de bajo contenido en carbono, tratándose de un ejemplo más de que la mayoría de los objetos metálicos, protohistóricos, poseen esta composición, hecho que nos ha invitado a reproducir las estructuras encontradas con aceros modernos, también llamados dulces.

Las piezas arqueológicas analizadas, de las que se han tomado muestras, tienen la característica común de haber sido sometidas a ritos de cremación, lo que quiere decir, que sufrieron un ciclo térmico final determinado por la incineración, no habiendo sido encontradas dichas estructuras en materiales no sometidos a los mismos ritos, lo cual nos lleva a estudiar el ciclo térmico que se produce en estas piezas durante su exposición al fuego crematorio.

En este estudio es fundamental conocer la temperatura máxima alcanzada y que ésta se mantenga durante un tiempo suficiente. Para responder a la pregunta de por qué es importante que se alcance y mantenga esta temperatura, es necesario hacer referencia al diagrama de equilibrio hierro-carbono, realizado por el profesor Criado (Criado 2008: 8) (fig. 1).

Los aceros cambian significativamente su estructura si alcanzan el campo austenítico, en el cual todo el carbono se disuelve en el hierro formando la fase austenita, que sólo es estable a alta temperatura. Durante este proceso, la microsestructura anterior desaparece y es sustituida por la austenita. Si no se alcanza la temperatura mínima de $723{ }^{\circ} \mathrm{C}$ no hay transformación austenítica. En el caso de los aceros con bajos contenidos en carbono, que es con los que hemos trabajado, la temperatura mínima, para la transformación en austenita, es $912^{\circ} \mathrm{C}$.

Apoyándonos en los resultados obtenidos por el Grupo de Investigación de Tecnología Mecánica y Arqueometalurgia de la Universidad Complutense de Madrid, en el estudio de piezas arqueológicas sometidas a ritos de cremación, en concreto de aceros con bajo contenido en carbono, que presentaban una microestructura atípica, se han marcado los siguientes objetivos para este trabajo:

- Determinar la temperatura de incineración y las velocidades de enfriamiento a las que fueron sometidas las piezas durante la cremación.

- Simular dicho tratamiento térmico en aceros modernos con el objetivo de reproducir las microestructuras encontradas.

- Conocer, una vez logrados los dos objetivos anteriores, que piezas fueron sometidas a la cremación con el cadáver y cuáles no sufrieron esta exposición al fuego y fueron depositadas con el ajuar junto a la urna cineraria.

- Cuáles son los mecanismos cinéticos y termodinámicos que nos llevan a estas peculiaridades microestructurales.

\section{El rito funerario de la cremación entre los íberos y los celtíberos}

El rito funerario generalizado entre los pueblos íberos y celtíberos fue el de la cremación del cadáver. La reconstrucción de estos ritos es sumamente complicada. En muchas ocasiones la tumba con los restos 


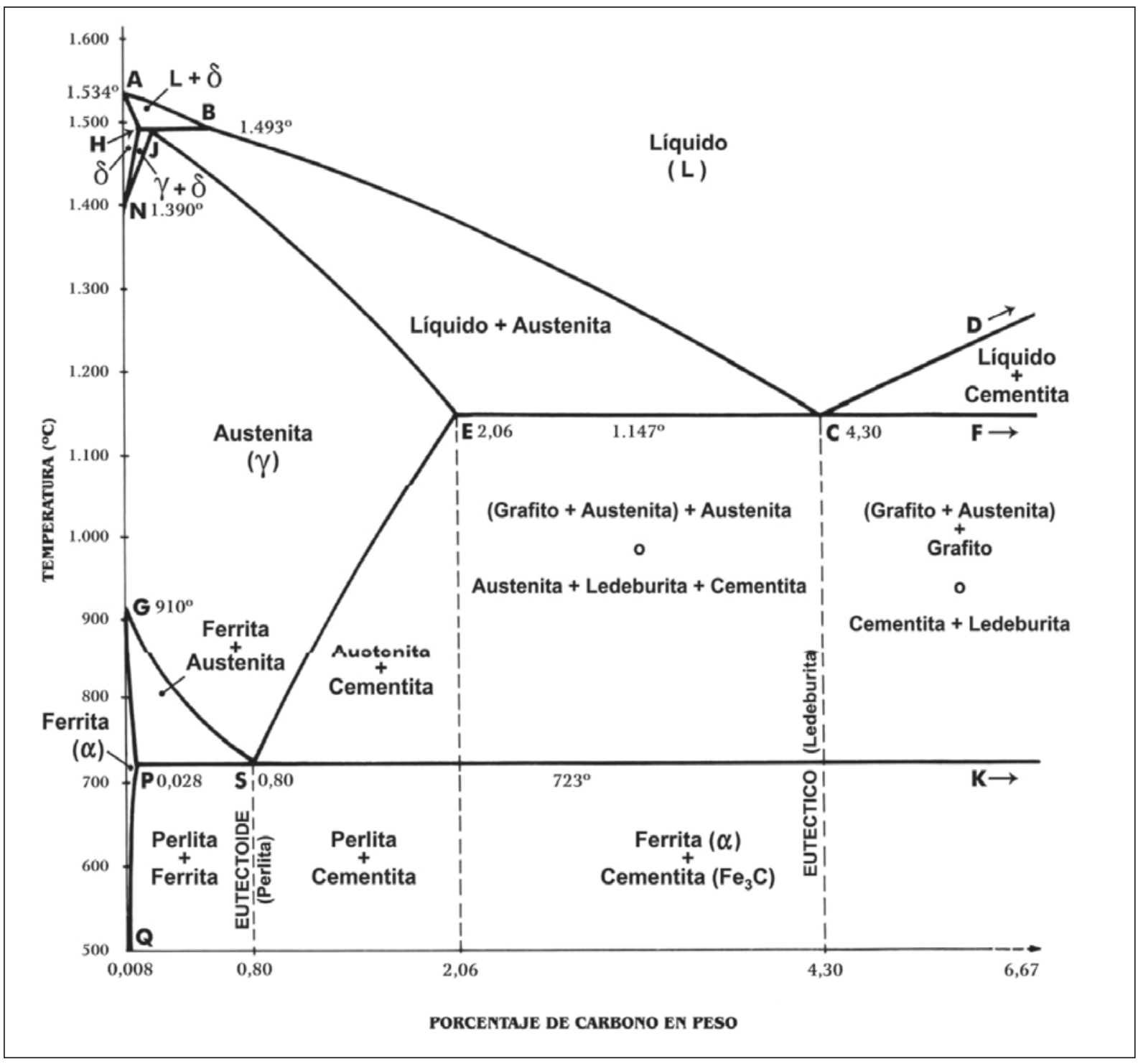

Figura 1. Diagrama de equlibrio hierro-carbono.

incinerados es la única evidencia de que se dispone para tratar de reconstruir la ideología y el simbolismo que hay detrás de esta compleja ceremonia fúnebre. Cerdeño afirma en este punto (García Huerta 2001: 179) que el ámbito funerario de una comunidad es revelador de muchas de sus actitudes culturales como la estructura social, aspectos económicos, demografía, manifestaciones rituales y también de las que menos huellas dejan en el registro arqueológico, como las creencias religiosas y la esfera simbólica del pensamiento.

En primer lugar expondremos, en el ámbito de los íberos, lo que se ha escrito hasta el momento sobre su ritual funerario y aspectos importantes de éste para el trabajo como son el tratamiento del ajuar y las temperaturas alcanzadas en la pira funeraria.

Blázquez (1976: 89-94) afirma que el rito funerario de los íberos era el de la cremación y que a los guerreros se les enterraba con sus armas, depositándose vasos de ofrenda que se debían arrojar, igual que las armas, en la pira, ya que frecuentemente llevan señales del fuego. En otro artículo, este mismo autor (Blázquez 1990: 223-233) sugiere que el ajuar unas veces se quemaba con el cadáver y otras no.

Ruiz (1995: 207-232) destaca que desde mediados del siglo $\mathrm{V}$ a. C. se generaliza entre los íberos el armamento, no sólo en las tumbas tumulares principescas 
o de cámara, sino incluso en las más sencillas, lo que supone, junto al factor constructivo, una cierta tendencia isonómica que se observa en otros niveles del ajuar, con lo que la recuperación y exposición de elementos aislados, se constituye cualitativamente en un fundamento para la diferenciación de grupos sociales que tratan de autoreproducirlo en su ritual de la muerte. Haciendo referencia a Cuadrado (Ruiz 1995: 232) opina que el ajuar podría expresarse como un factor cronológico señalando la existencia de un ritual destructivo que consiste en la deposición durante la cremación de una importante parte del ajuar. Por el contrario, a partir del siglo III a. C., afirma que se impone un ritual conservador en el cual se deposita el ajuar después de realizada la cremación.

Fernández de Castro (1997: 320-326) observa que en el ritual funerario ibérico no se produce ningún cambio desde el siglo $\mathrm{V}$ a.C. hasta el período romano en todo el territorio suroriental, siendo las armas de hierro (falcatas, lanzas, soliferra, escudos y cuchillos), objetos típicos que se encuentran en toda suerte de sepulturas, pero casi exclusivamente durante el siglo IV a. C. Los valores guerreros y belicosos se tenían en gran estima, como demuestran los hallazgos de espadas de gran calidad con un rico decorativismo.

Belén (1997: 182-190) afirma que el desarrollo del proceso ritual en el mundo ibérico es bien conocido gracias a yacimientos como Castellones de Ceal (Jaén), Los Villares de Hoya Gonzalo (Albacete), Cigarralejo (Murcia), Cabezo Lucero (Alicante) o Turó dels Dos Pins (Barcelona). Cuando una persona moría era transportada hasta el recinto funerario, donde se procedía en primer lugar a la cremación del cadáver. Esto se realizaba en una pira consistente en una somera fosa excavada en el suelo en la que se disponían ramas de madera mezcladas con matorrales que favorecían la ignición. Durante el proceso funerario podían ofrecerse banquetes rituales que implicaban la destrucción y el enterramiento de la vajilla utilizada, como se ha constatado en el silicernium de la necrópolis de Hoya Gonzalo. Terminando este proceso, se depositaban los huesos del difunto dentro de cada tumba, generalmente introducidos en una urna cerámica, acompañándola algunos objetos personales y elementos de ajuar. Añade que el cadáver se quemaba vestido y acompañado por sus armas, otros objetos personales y elementos de ajuar, predominando las piezas de vestido y adorno (broches de cinturón, pendientes, cuentas de collar, botones), las armas de hierro y recipientes de bebida y ofrenda. En ocasiones se incorporaban elementos propios del trabajo que desarrolló en vida, como instrumentos agrícolas, juegos de pesas, útiles de orfebre, etc. Coloca la temperatura de la pira en superior a $600^{\circ} \mathrm{C}$ debido al color y la textura de los pequeños restos óseos resultantes.

Por otro lado García Raya (1999: 291-307) nos informa sobre el hecho de que el difunto sufría una serie de ritos antes, durante y después de su cremación. Vestido con su mejor indumentaria, joyas y armas, si pertenecía en este último caso a la casta guerrera, era depositado en la pira funeraria. Respecto a los ajuares bélicos opina que eran quemados la mayoría de las veces con el cadáver, quizá con la intención de que acompañaran al difunto, como objeto muy personal, explicando así que previamente habían sido dobladas, unitilizándolas ritualmente.

Para San Nicolás Pedraz (2000: 159-166) el ritual generalizado entre los pueblos íberos fue el de la cremación del cadáver. El ceremonial consistía en el transporte del cadáver al recinto funerario en el cual, en una pira sobre la tierra o en un somero hoyo, era quemado. Es probable que, entre las diversas ceremonias que se celebrasen, durante o después, de la cremación, se dieran banquetes con vino u otras bebidas, que finalizaban con la destrucción y enterramiento de la vajilla utilizada. A continuación se procedía a depositar los restos del difunto en su tumba, generalmente dentro de una urna cerámica o de una cista de piedra, como la del Cerro del Real (Granada) o la del Peal de Beceno (Jaén). Por último, el rito de la cremación, conocido por estudios realizados en múltiples e importantes necrópolis, consistía en un complejo ceremonial, en cuya una de las partes era el quemar el cadáver vestido junto con su ajuar. Sitúa la temperatura de la pira entre $\operatorname{los} 600^{\circ}$ y $\operatorname{los} 800^{\circ} \mathrm{C}$.

Pereira afirma (García Huerta 2001: 11-35) que la información obtenida del registro arqueológico presenta por el momento una serie de lagunas, ya que los trabajos de documentación se han orientado más hacia el análisis de las tumbas que de los lugares donde se efectuaban las cremaciones, debido a que en muchos casos se carece de información precisa sobre la localización de las mismas, sus medidas y morfología, tipos de combustible empleados, la posición del cadáver en la pira, elementos depositados en la misma y el tratamiento que recibían los restos cremados una vez que se apagaba la pira. Tampoco se cuenta con información suficiente sobre el tiempo que duraba la cremación del cadáver. Para este autor una sistematización del registro arqueológico del ámbito funcional de las cremaciones, permitiría una reconstrucción más fiable del ritual funerario y de sus distintas variantes, tanto en el ámbito de la necrópolis como en aquellos casos en que 
se destinaran espacios adjetivos a dicha funcionalidad, ampliando las propuestas de reconstrucción ritual. Un apartado fundamental para el estudio de las cremaciones, aparte de otros factores como los datos topográficos o la evolución de los usos en el rito, sería el análisis de los restos documentados en el interior de los quemaderos. Señala la existencia de distintos elementos de cultura material entre los que destacan restos cerámicos de los recipientes de las ofrendas o el banquete funerario, junto con la localización de otros materiales como armas, objetos de hierro y bronce. Así un aspecto importante en el estudio de estos materiales es el correspondiente a los que pertenecen al atavío y el adorno personal del cadáver, que en su mayoría aparecerán claramente identificados como piezas del ajuar funerario del ritual de la cremación.

Para Blánquez (García Huerta 2001: 104-108) el rito funerario de enterramiento, una vez apagada la pira, fuera de la necrópolis, $y$, por lo general, introducidos los huesos cremados dentro de una urna, se realizaba el desplazamiento a la misma de cara a depositarlos en un hoyo practicado dentro del suelo de la necrópolis que, previamente, habría sido delimitado dado el carácter ritualizado, y no de improvisación, de todo el acto. Defendiendo esta previsión cree que no se puede generalizar a la totalidad de los enterramientos, aunque sí parece que para los tumulares. A continuación se tapaba la urna con una piedra, plato o fuente colocado de manera invertida y materializando así un primer cierre. Respecto al ajuar y a la temperatura de cremación, el autor afirma que en el interior de la urna sólo se depositaban los huesos limpios por la acción del fuego a más de $700^{\circ} \mathrm{C}$ y, en numerosas ocasiones, acompañados de objetos personales y de adorno como fíbulas, anillos, pendientes y placas de cinturón. Las frecuentes alteraciones de estos objetos provocados por el fuego, permiten colegir que el cadáver era quemado vestido y no envuelto en un sudario. Ello, apunta a su vez, el posible carácter público de la cremación, equipado con sus mejores galas (vestido y adorno) evidenciadoras de su elevado estatus.

Más en concreto, en el campo del ajuar, denota que frente al avance en el conocimiento que supone ser conscientes de que dentro de las tumbas ibéricas parte de los objetos depositados son consecuencia material de celebraciones ritualizadas, paralelamente, ello mismo, plantea nuevas cuestiones a resolver. Surge la necesidad de diferenciar, siempre que sea posible, que materiales corresponden propiamente al ajuar del difunto y cuales, por el contrario, son consecuencia de determinados actos rituales acometidos en su honor. Dicha diferenciación, metodológicamente hablando, es básica como punto de partida tanto para comprender en toda su complejidad el rito funerario ibérico como para si se quiere establecer valoraciones sobre la supuesta "riqueza" o "pobreza" de los ajuares de los individuos allí enterrados. Blánquez sugiere que durante décadas las excavaciones han desatendido aspectos fundamentales de cara a poder establecer estas matizaciones. Como ejemplo pone la ubicación y asociación de los objetos dentro de la tumba o el orden en el proceso de deposición dentro de ella. El problema se dificulta aún más al ser conscientes de que en una y otra valorización (ritual de enterramiento / ajuar funerario) los materiales que lo materializaban eran similares: recipientes para perfumes, armas o cerámicas griegas aparecen utilizadas, indistintamente, en una y otra función.

Salinas de Frías (2006: 91-92) nos hace otra descripción del rito crematorio. Apunta que la combustión del cadáver se hacía en un ustrinum, junto con el ajuar. Las cenizas luego se depositaban en una urna o vaso de cerámica que se depositaba en la tumba. La forma, dimensiones y aspecto de ésta varían de acuerdo con la importancia social y económica del difunto, con ajuares consistentes en algunos platos, alguna hebilla y objetos metálicos. Para este autor la combustión del cadáver se hace junto con el ajuar y notifica que en las tumbas de guerreros aparecen armas como falcatas, puñales, umbos de escudo, normalmente destruidas o dobladas intencionalmente para que nadie pudiera utilizarlas.

Por último López Cachero (2008: 139-171) presupone la existencia de diferentes etapas desde la muerte del individuo hasta la deposición de sus restos en la tumba. Entre ellas destaca la preparación ceremonial del cuerpo del difunto, el transporte y acompañamiento del cadáver hasta la pira funeraria, la celebración de un banquete funerario, la combustión y recogida de los restos y, finalmente, su definitiva deposición en la tumba. Opina que algunos autores han propuesto que la preparación del cadáver implicaba su ornamentación con ciertos objetos personales. Esto explicaría por qué algunos elementos metálicos se encuentran deformados o parcialmente fundidos, aunque reconoce que no todos los objetos metálicos que aparecen en el interior de una tumba se encuentran afectados por la combustión, lo cual permite pensar en una deposición posterior a este acontecimiento. Sitúa la temperatura alcanzada en la pira en un margen entre $\operatorname{los} 650^{\circ} \mathrm{y} \operatorname{los} 800^{\circ} \mathrm{C}$.

En cuanto a los celtíberos, su ritual funerario no varía respecto al de los íberos ya que se trata de dos culturas en íntima conexión. De hecho, según García Huerta 
(VVAA 1992: 221), el mundo ibérico resultó fundamental en la configuración de la cultura celtibérica, que una vez constituida adquirirá una entidad propia, creando su propio repertorio material formando, como se ve en el repertorio del ajuar funerario, una sociedad jerarquizada, aunque económicamente más débil que la ibérica, en las que prácticamente el único material de importación procede del área ibérica.

Belén (1997: 199-202) opina que como es común en toda la Edad del Hierro entre los grupos peninsulares cuyas necrópolis nos son conocidas, entre los celtíberos los cadáveres ardían en un quemadero o ustrinum y una vez separados de las cenizas y carbones, los huesos calcinados se recogían en urnas de cerámica hecha a mano, metidas en un hoyo y tapadas con un cuenco o una piedra plana, o se depositaban directamente en el suelo, dentro del hoyo, acompañados en ambos casos de sus objetos personales y de ofrendas. Los ajuares muestran con claridad la consolidación, a partir del siglo VI a. C., en las tierras altas de las cabeceras del Duero, Tajo y Jalón, de una sociedad jerarquizada en cuya cúspide se sitúan las élites guerreras. En las sepulturas de guerreros se encuentran, además de armas, objetos de adorno. Con todo existen grandes diferencias en la composición de los ajuares de guerreros y son pocos los enterramientos que presentan equipos armamentísticos completos.

Cerdeño también afirma (García Huerta 2001: 163 169), que el ritual documentado en las necrópolis celtibéricas es el de la incineración o cremación del cadáver en una pira funeraria y en un lugar específicamente dedicado a ello. Opina que los datos concretos sobre la técnica de incineración son todavía escasos, empezando porque no se sabe si cremaban el cadáver o el esqueleto después de prácticas descarnatorias o similar. En cuanto a la temperatura la sitúa entre $850^{\circ}$ y $950^{\circ} \mathrm{C}$, basándose en estudios de Reverte (García Huerta 2001: 165). El autor hace otra alusión a la temperatura, refiriéndose a la necrópolis de Numancia, colocándola entre los $600^{\circ}$ y los $800^{\circ} \mathrm{C}$ (García Huerta 2001: 165; Jimeno 1993: 31-44). Además Cerdeño nos cuenta que las fuentes literarias dan noticia sobre el hecho de que durante la cremación solían quemarse en la pira hierbas y perfumes y se realizaban sacrificios, libaciones y ofrendas, y era costumbre arrojar al fuego algunos recipientes empleados en estos rituales. Acabada la cremación se procedía a la recogida de los restos, sin una regla fija de cuidado para ésta, que se colocaban en una urna cerámica o serían envueltos en una tela o en piel de animal para su definitiva deposición en el hoyo junto al ajuar. Reconoce el desconocimiento del exacto código ritual que regía el mecanismo de la existencia de objetos en las sepulturas, de las cuales, algunas aparecen con muchos objetos y otras con ninguno. Las piezas depositadas en las tumbas ofrecen docenas de ellas diferentes, de algunas de las cuales es difícil determinar su funcionalidad. Principalmente se trata de objetos de adorno y uso personal, de armas, de las cuales las más significativas son espadas, puntas de lanza, regatones, cuchillos de hoja curva y soliferra, todas fabricadas en hierro, que en la mayor parte de los casos aparecen inutilizadas intencionalmente. Esta manipulación deliberada responde a motivos directamente relacionados con una estructura social en la que destacaba una élite de carácter guerrero, entre la que adquiría un gran valor ético la guerra, real o ficticia, y la muerte en combate.

Lorrio (2005: 123-134), en la misma línea que el resto de los autores, opina que el ritual funerario documentado en los cementerios de los celtíberos es el de la cremación, pero habida cuenta de que únicamente se conoce el resultado final de este proceso, queda reducida toda evidencia del mismo al ajuar y al tratamiento de que éste fue objeto o a las estructuras funerarias con él vinculadas. Según su opinión el cadáver sería cremado en una pira, seguramente localizada en áreas específicas del cementerio, en posición de cúbito supino. Los restos de la cremación, entre los que se hallarían algunos de los objetos que formaban el ajuar, pues otros no evidencian señales de haber estado en contacto con el fuego, serían recogidos y depositados en el área específica reservada al enterramiento, en el interior de un hoyo preparado al efecto, directamente en el suelo, envueltos en una tela o quizás en recipientes de material perecedero, o en una urna cineraria. La ubicación del ajuar también varía, colocándose a veces al lado de la urna, otras debajo de la estela, apareciendo, por lo común, los objetos de adorno dentro de la urna, y las armas, generalmente de mayor tamaño, fuera, alrededor de la misma. Respecto a éstas afirma que existe un grupo destacado de sepulturas que se define por la presencia de armas (espadas, puñales, lanzas, jabalinas, escudos y cascos), siempre en diferentes combinaciones y a las que suele asociarse cuchillos, así como arreos de caballo y útiles tales como el punzón o, de forma menos usual, la hoz o las tijeras. También se documentan objetos relacionados con la vestimenta, como los broches de cinturón o las fíbulas. Haciendo referencia a la necrópolis de Numancia, destaca la uniformidad de los restos humanos depositados en los enterramientos, muy escasos y seleccionados, ya que sólo aparecen restos pertenecientes al cráneo y a huesos largos, así como frecuentemente fragmentados, quizás de forma 
intencionada. Afirma que la temperatura a la que se efectuó la cremación oscila entre los $600^{\circ}$ y los $800^{\circ} \mathrm{C}$.

Por último Salinas de Frías (2006: 129) afirma que el ritual generalizado en Celtiberia, basándose en los restos arqueológicos, es el incinerador, acompañando a las cenizas del difunto un ajuar más o menos rico, según la clase social del individuo, siendo, en los casos de tumbas guerreros, su acompañamiento, armas inutilizadas ritualmente.

Una vez expuesto lo que se conoce hasta el momento del ritual funerario de la cremación entre los íberos y los celtíberos, debemos añadir lo que se ha escrito también respecto a la importancia ritual del agua, ya que en la presente investigación se ha detectado, en las piezas metálicas expuestas al fuego, que la pira podría haberse apagado con algún tipo de líquido, ya que los objetos metálicos muestran que sufrieron un fuerte gradiente térmico, desde la máxima temperatura alcanzada, y que dan origen a las microestructuras objeto de este estudio.

En este sentido Blánquez (García Huerta 2001: 94100) se refiere a la presencia-utilización del agua como elemento acotador de los espacios funerarios. En la Península Ibérica, durante el período colonial fenicio-púnico, encontramos antecedentes de dicha utilización referida tanto a ambientes funerarios como puramente sacrales; bien como elemento limitador, bien como elemento protagonista en determinados rituales. Así, en la necrópolis de Las Cumbres (Puerto Santa María, Cádiz) perteneciente al Castillo de Doña Blanca, se ha documentado la existencia de toda una red de pequeños canales que, aprovechando la pendiente natural de la Sierra de San Cristóbal, rodearían los grandes túmulos funerarios. Paralelamente, en la ciudad púnica de Carteia (San Roque, Cádiz) se ha encontrado otro dato revelador: en la parte central del asentamiento, la más elevada del entorno, se ha identificado el área religiosa de la ciudad y, junto a ella, un notable desagüe en caliza fosilífera que evacuaría, muy posiblemente, el agua utilizada en determinados rituales acometidos en aquel espacio sacro. De hecho son frecuentes los testimonios documentados en esta misma línea dentro de las ciudades púnicas del norte de África. Encontrados testimonios arqueológicos acerca del protagonismo del agua en determinados actos sacrales, cuando no directamente funerarios, si se habla del posterior período ibérico los ejemplos se multiplican. A este respecto en Archena (Murcia) todavía hoy se encuentra un balneario de aguas medicinales en explotación, aunque es a través de los estudios paleoambientales de los espacios funerarios, donde se ha obtenido la documentación más interesante. Así en la necrópolis de Los Villares (Hoya Gonzalo, Albacete) los estudios polínicos documentan la existencia de una vegetación propia de un ambiente de alto nivel de humedad, próxima a un paisaje casi pantanoso. En esta línea, el propio nombre de la localidad en donde se encuentra el yacimiento (Hoya Gonzalo) nos recuerda la topografía hundida de la necrópolis con respecto a su entorno.

También tenemos noticias sobre el papel del agua entre los celtíberos. Cerdeño (García Huerta 2001: 159) afirma que un dato interesante de los cementerios de estos pueblos, quizás obvio por situarse en las zonas llanas que forman los valles de los ríos, es que se encuentran cerca del agua, que en muchas culturas antiguas, especialmente en la celta, tuvieron un alto significado simbólico, representando la separación del mundo de los vivos del de los muertos. Los cursos de agua pueden representar el vehículo que transporta el alma al más allá, el elemento de tránsito hacia la otra vida. En este sentido Lorrio apunta (Lorrio 2005: 111) que resulta habitual la proximidad de las necrópolis a cursos de agua, posiblemente debido a la existencia de rituales de tránsito en los que el agua jugaría un papel esencial.

Lo que se desprende de la información dada por los autores es el acuerdo unánime en que el rito funerario generalizado entre los íberos y los celtíberos fue el de la cremación del cadáver. Lo que no parece claro, dentro del campo de nuestra investigación, es cuales objetos metálicos de hierro se incineraban con el cadáver y cuales se depositaban después junto a las cenizas del difunto. Tampoco se conoce con exactitud las temperaturas alcanzadas en la pira, ya que pocos autores hablan de ellas y los que lo hacen se refieren a otros trabajos en los que no se ha tenido en cuenta el estudio de los objetos de acero, vector fundamental de información. El presente trabajo ofrece una herramienta válida para cualquier arqueólogo que afronte el estudio de una necrópolis ibérica y celtibérica, pudiendo completar la información obtenida de ella con el análisis de los objetos de hierro, que dan unos conocimientos precisos y altamente fiables sobre los procesos rituales que se dieron entre estos pueblos.

Como conclusión a este apartado citaré palabras de Blánquez (García Huerta 2001: 127) en las que se refleja bastante acertadamente el espíritu del presente trabajo de investigación: "Notable ha sido, pues, el avance del conocimiento en torno al mundo funerario ibérico $\mathrm{y}$, más concretamente, cómo es posible hoy profundizar en su verdadero significado, fundamentalmente gracias al detallado análisis y estudio arqueológico de campo. Pero todavía más importantes han sido los cambios en 
los modos y maneras de estudiarlo. Una diferente actitud metodológica ha hecho posible esta nueva andadura durante las tres últimas décadas, hasta el punto de haber llegado a dibujar, reconstruyendo, su propio paisaje funerario. Pero, aún con ello, mayor es el camino que queda por recorrer. Nuevos avances tecnológicos y nuevas investigaciones harán posible el progreso de nuestro conocimiento y conllevarán, como no podía ser de otra manera, nuevos interrogantes pendientes por estudiar. Sigamos, pues".

\section{Estado de la cuestión}

Sobre el tema que acometemos en esta investigación se tienen pocas noticias directas de autores clásicos, sobre los ritos funerarios que se practicaban entre los pueblos prerromanos de la Península Ibérica. La Arqueología y la Arqueometría se convierten así en fuentes fundamentales de conocimiento. El análisis de estos ritos como herramienta para el estudio antropológico es una experiencia relativamente nueva. En las siguientes líneas se expondrán las investigaciones más destacadas sobre este tema.

En primer lugar tenemos el trabajo realizado por Wells (1960: 29-37) en el que se estudia una serie de restos óseos encontrados en un campo de urnas de Norfolk (Inglaterra), siendo una de las primeras muestras de este tipo de estudios. Como él mismo describe, la mayoría de los trabajos previos se centran en poco más que asignar el sexo y la edad de los individuos encontrados. En este primer estudio, Wells, además de determinar el sexo y la edad de los restos humanos, con los datos obtenidos realiza una descripción de la técnica de cremación, basándose en el estado de calcinación de los huesos hallados. Propone que el cuerpo era situado próximo al suelo, en posición supina y con la pira extendida sobre él y concluye fijando la temperatura alrededor de $\operatorname{los} 900^{\circ} \mathrm{C}$, que es la necesaria para que fundan las pequeñas gotas de vidrio encontradas junto a los huesos.

Gómez Bellard (1996: 55-64) señala que durante décadas no se habían considerado los huesos quemados como fuentes de información antropológica y arqueológica. Indica que para el estudio de culturas como la ibérica, la fenicia, la púnica o la romana, en las que la cremación fue utilizada durante siglos, los estudios de estas fuentes son muchas veces la única vía de información. En su trabajo propone una metodología en la que destaca los problemas típicos que se suelen encontrar y los errores que se suelen cometer. Afirma que la forma adecuada para conocer la temperatura alcanzada es el estudio de la coloración de los huesos. Cita entre otros los estudios de Hummel (1988: 177-194) y Etxeberría (1987: 105-112).

Un estudio más reciente que estudia también la relación entre el color de los huesos quemados y las condiciones en que tuvo lugar la cremación (tiempo, temperatura y disponibilidad de oxígeno), es el realizado por Philips (2005: 222-233). Se trata de un trabajo sistemático en el que se varían las distintas condiciones llegando a obtener diversas tablas de referencia como, por ejemplo, los colores encontrados en una cremación en un horno en atmósfera de aire, tierra diatomea y "topsoil", frente a los hallados en un entorno con alto contenido orgánico.

El estudio del color de los huesos no es la única técnica que se ha utilizado para conocer las temperaturas de las cremaciones. Se destacan trabajos como el de Enzo (2007: 1731-1737) y el de McKinley (1997: 129145), que utilizan otros métodos para determinar dichas temperaturas. El trabajo de Enzo consiste en el estudio de la cristalinidad de los huesos observada mediante Difracción de Rayos X y comparada con unas muestras patrón preparadas a diferentes temperaturas. El hueso fresco es un compuesto amorfo que al ser sometido a un tratamiento térmico sufre una progresiva cristalización, que corresponde a un crecimiento de los cristales de fósforo cálcico. La conclusión a la que llega con los difractogramas de las muestras estudiadas y las muestras patrón es que las temperaturas máximas alcanzadas en algunos huesos son $\operatorname{los} 750^{\circ} \mathrm{C}$.

En el estudio de Mckinley destaca la realización de una simulación de cremación y el registro de las temperaturas alcanzadas en cada una de las zonas de la pira. Utiliza para tal objetivo una serie de termopares, concluyendo a través de este experimento, que se alcanzan temperaturas mayores a los $1000^{\circ} \mathrm{C}$, manteniéndose durante tres horas aproximadamente.

Además de los huesos, Reverte (1985: 195-282) constató, en la necrópolis del yacimiento de Pozo Moro (Albacete), la cremación conjunta de mujer-niño en varias ocasiones, en función de alguna enfermedad infecciosa aguda, o incluso de alguna forma de eutanasia no confirmada. En este estudio comprobó, con técnica criminalista, que la temperatura lograda en el proceso de cremación debió de ser entre $850^{\circ}$ y $950^{\circ} \mathrm{C}$, máxima alcanzada por la combustión de maderas como el Quercus Ilex, y que los cuerpos se quemaron sobre la tierra o en hoyos excavados en ésta, en posición decúbito supino.

En resumen no se han empleado para conocer temperaturas máximas piezas metálicas. Sí ha sido empleado 
el estudio de la coloración de los huesos, de entre los cuales, por el rigor establecido en el trabajo realizado, el de Philips es el que tiene una mayor validez científica. Es destacable el trabajo arqueológico experimental de MacKinley en el estudio de una cremación y el de Enzo, empleando una técnica tan reproducible como la Difracción de Ratos X, para el estudio de los huesos calcinados. Las temperaturas máximas alcanzadas según las diferentes investigaciones de distintas cremaciones rondan los $900^{\circ} \mathrm{C}$, salvo en el caso del estudio de Enzo. Este hecho invita a pensar que los objetos de hierro que fueran sometidos a ritos de cremación, hayan estado en el campo de estabilidad austenítico, al menos a esas temperaturas.

A raíz de esta comprobación, durante el estudio mediante Microscopía Electrónica de Barrido que realizó el grupo de varias piezas, con una alta fiabilidad de que fueron sometidas a ritos de cremación, se detectó la presencia de una microestructura no habitual en los aceros modernos. Su micromorfología podría describirse como una matriz ferrítica en cuyo interior aparecen precipitados aciculares con unas orientaciones preferenciales. Se hizo necesaria una revisión bibliográfica para encontrar antecedentes sobre esta cuestión.

Piaskowski (1961: 263-282) es el antecedente más antiguo con el estudio metalográfico de este tipo de estructura encontrada en una serie de objetos de hierro hallados en Polonia. Este autor señala que la mayoría de las piezas encontradas, procedentes del período de estudio, fueron sometidas a ritos de cremación. Afirma que las microagujas, antes descritas, son nitruros de hierro, más concretamente de fases $\gamma^{\mathrm{I}}-\mathrm{Fe}_{4} \mathrm{~N}$ y $\alpha^{\mathrm{II}}-$ $\mathrm{Fe}_{16} \mathrm{~N}_{2}$, justificándolo con los resultados obtenidos por Broker (Broker 1957: 205-216), el cual analiza mediante Difracción de Rayos X precipitados aciculares en piezas arqueológicas, intentando reproducir dicha estructura nitrurando hierro prácticamente puro.

Otra investigación importante es la efectuada por Shugar (2003: 109-118). En ésta realiza un estudio sobre tijeras romanas, encontrando en varias de ellas la microestructura en forma de agujas. Defiende que los precipitados encontrados son nitruros de hierro y trata de justificarlo mediante un análisis de Microsonda Electrónica.

Otro antecedente destacable de este tipo de estructuras es el trabajo de Liu (1984: 261-264), en el realiza un estudio mediante Microscopía Electrónica de Transmisión y Difracción de Rayos X, de unos aceros antiguos encontrados en Jordania. Concluyen a través de los resultados obtenidos que los precipitados aciculares son carburos de hierro y no nitruros. La presencia de estos precipitados en zonas cercanas a agujas Widmastätten de fase ferrita, junto con la aparente direccionalidad que poseen, sugiere que los mismos puedan haber evolucionado a partir de los carburos iniciales presentes en las interfases de las agujas Widmanstätten, produciéndose un envejecimiento que conlleve la formación de estos precipitados aciculares.

Destacar por último el estudio realizado por Criado (2006: 1-5) sobre los cambios microestructurales que se producen en los aceros por envejecimiento natural (a temperatura ambiente), en períodos de tiempo muy largos. En el mismo se defiende la tendencia hacia unas microestructuras más ordenadas y regulares debido al efecto del tiempo, en particular la evolución que sufre la fase cementita, fragmentándose y adquiriendo morfologías más idiomórficas. Sus resultados se basan en el estudio de aceros antiguos por Microscopía Electrónica de Barrido.

\section{TÉCNICA EXPERIMENTAL}

\section{Preparación de las muestras arqueológicas}

Para la preparación de las muestras arqueológicas se requiere una serie de pasos muy precisos. En primer lugar se extrae una pequeña muestra mediante el empleo de una microcortadora con disco de diamante marca REMET tipo MICROMET.

Una vez extraída se embute en resina epoxy (CRONOLITA 1112), para facilitar el manejo durante la preparación de la misma, que consiste en obtener una superficie totalmente lisa para su observación mediante Microscopía Óptica y Electrónica de Barrido. Esta preparación consiste en dos fases: desbaste y pulido.

En la primera se procede al desbaste de las muestras mediante el empelo de papeles con abrasivos resistentes al agua marca BUEHLER, con distinto tamaño de grano y el uso constante del agua como lubricante, que además elimina posibles restos de granos desprendidos del papel, que podrían llegar a contaminar la muestra o el siguiente papel de granulometría más fina.

En primer lugar se usa el papel con el tamaño de grano mayor (120), hasta que toda la superficie muestre marcas de desbaste paralelas entre sí. Una vez obtenido esto se procede a desbastar con el siguiente papel de la serie (240) y de la misma manera, con la salvedad de girar $90^{\circ}$ la probeta para eliminar las marcas del papel anterior. Sólo cuando se las ha eliminado se puede asegurar que se ha rebajado o preparado la superficie para desbastar en el siguiente papel. Este proceso se realiza 
sucesivas veces cambiando a papeles de la serie con menor tamaño de abrasivo, siendo el tiempo requerido para cada uno de los papeles mayor que el del papel anterior $(320,400,600,900)$. Al final se tendrá la muestra lista para el proceso del pulido.

Antes de pasar a esta segunda fase es necesaria una escrupulosa limpieza con el fin de no contaminar la muestra. El pulido tiene como fin eliminar las líneas producidas por el último papel de desbaste y se realiza con una máquina pulidora de la marca REMET tipo LS2 y un paño impregnado con Alúmina $\alpha$ de 0,3 $\mu \mathrm{m}$ (micrómetros). La muestra se pone en contacto con el paño húmedo y la Alúmina actúa eliminando las líneas, dejando una superficie totalmente lisa y pulida. A medida que la pulidora gira la muestra debe girarse suavemente en sentido contrario para obtener un pulido homogéneo hasta conseguir que la superficie metálica muestre un aspecto especular. Para lograr una superficie de mayor calidad se realiza un pulido final con Alúmina de granulometría más fina (Alúmina $\gamma$ de 0,05 $\mu \mathrm{m})$. Tras cada etapa de pulido se comprueba la eliminación de las rayas de desbaste mediante su observación a la lupa. Para evitar la oxidación de la muestra debida al tratamiento con agua, se pulveriza la muestra con acetona, etanol o alcohol amílico y, a continuación, se seca con un secador de aire caliente.

Una vez se ha conseguido un pulido especular se ataca la superficie para revelar la estructura del acero, eligiendo como reactivos NITAL 4\% (4 $\mathrm{ml}$ de $\mathrm{HNO}_{3}$ concentrado en $96 \mathrm{ml}$ de etanol) y atacando durante 10-15 segundos y, en otras ocasiones, PICRAL (2g de ácido pícrico, $25 \mathrm{~g}$ de $\mathrm{NaOH}$ y $100 \mathrm{ml}$ de agua).

Para la observación mediante Microscopía Electrónica de Barrido es necesario que la muestra sea conductora. Debido a que las muestras están embutidas en resina epoxy, no presentan conductividad en la superficie. Por ello se recurre a un recubrimiento con material conductor (sputtering de oro o grafito según la naturaleza de la muestra). En nuestro caso se hizo con oro depositando una capa de décimas de micrómetro. El equipamiento utilizado para tal fin fue el de Sistemas de Sputtering para Recubrimiento con oro BIO RAD SC 502.

\section{Preparación de las muestras experimentales}

Se tomaron como muestras experimentales las del acero comercial AISI 1005 (0,06\% max. C; 0,45\% max. Si; 0,35\% max. Mn; 0,04\% max. P; 0,05\% max. S), proporcionado por el Taller Mecánico de la Universidad Complutense. Se eligió este acero bajo el criterio de asemejarse a las composiciones en carbono de las muestras arqueológicas.

En primer lugar se sometió la muestra a un tratamiento de austenización a $1000^{\circ} \mathrm{C}$, durante una hora, para solubilizar todo el carbono presente. A continuación la muestra fue normalizada (enfriada al aire). La muestra se sometió a un posterior tratamiento térmico en un Horno de Resistencia Eléctrica de Carbolite de potencia $8000 \mathrm{~W}$ (que puede alcanzar una temperatura máxima de $1300^{\circ} \mathrm{C}$ ) a una temperatura de $300^{\circ} \mathrm{C}$.

Debido a que el tratamiento térmico implicaba la exposición de la muestra a una atmósfera oxidante durante un largo período de tiempo (de unas horas a 10000 horas), existía un riesgo elevado de que se produjese una oscilación y decarburación de las muestras muy intensa. Por ello se decidió encapsularlas en ampollas de cuarzo siguiendo cuatro pasos básicos: introducción de la muestra en el tubo de cuarzo; sellado de uno de los extremos libres; generación de vacío en la cápsula desde el otro extremo; sellado de la cápsula mientras se produce el vacio, procediéndose de este modo para evitar el riesgo de explosión de la cápsula debido a la producción de gases durante el tratamiento térmico.

El tratamiento térmico se llevo a cabo con períodos de tiempo que oscilaron entre unas pocas horas y 10000 horas. Esta decisión fue tomada para poder ver la evolución, en la formación de los precipitados, de los carburos de hierro. Las cápsulas aguantaron todos los tratamientos térmicos sin romperse.

Posteriormente se rompieron con el objetivo de preparar la muestra para su observación metalográfica e introducir en otras cápsulas el resto de la muestra, con el cometido de continuar con las fases de tiempo creciente en el tratamiento térmico. Así sucesivamente, hasta sacar la última muestra con un tratamiento de 10000 horas.

De manera análoga a las arqueológicas se realizó la preparación metalográfica antes descrita. La diferencia con las muestras arqueológicas es que no fue necesario el sputtering de oro, debido a que eran conductoras en toda su masa.

\section{Microscopía Óptica, Microscopía Electrónica de Barrido (MEB), Microsonda Electrónica (EPMA)}

Las tres técnicas utilizadas para el estudio de las muestras arqueológicas y experimentales han sido el Microscopio Óptico Convencional, la Microscopia Electrónica de Barrido y la Microsonda Electrónica.

En primer lugar el Microscopio Óptico (fig. 2) se utilizó para evaluar el estado del pulido de la probeta y 


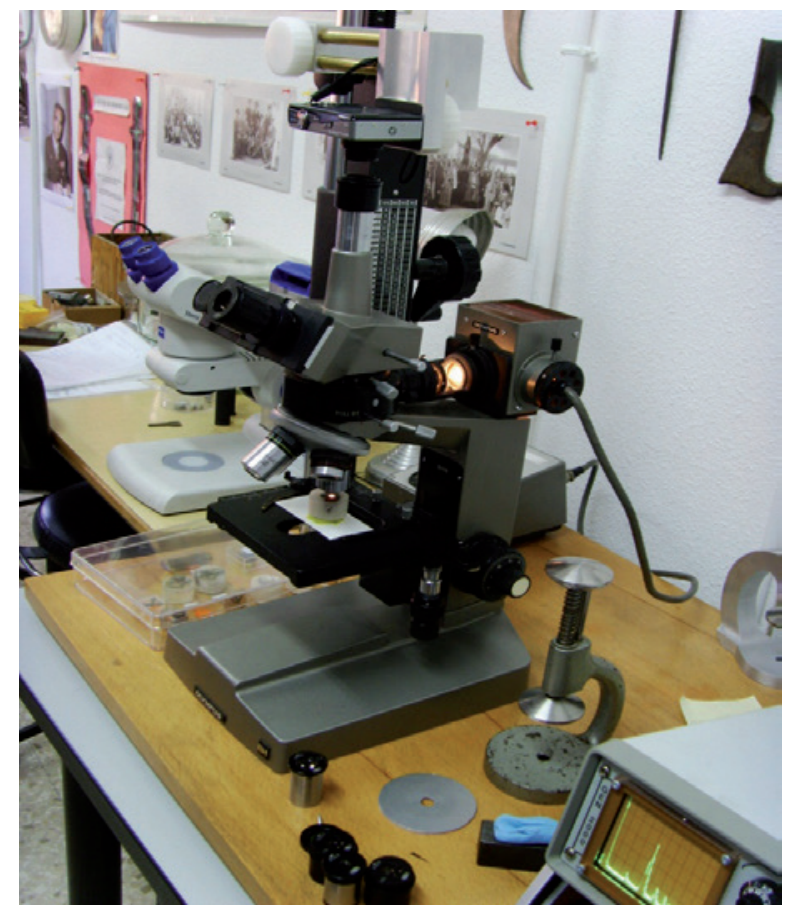

Figura 2. Microscopio Óptico.

el ataque con Nital o Picral. Además sirvió como una primera aproximación a la observación de la muestra. Se utilizó campo claro y campo oscuro, luz polarizada $\mathrm{y}$, en ocasiones, filtro verde para resaltar las microestructuras reflejadas en las micrografías.
Después del Microscopio Óptico se procedió a la observación de las muestras mediante Microscopía Electrónica de Barrido (Fig 3), en el CAI de Microscopia Electrónica Luis Bru de la Universidad Complutense de Madrid. Esta técnica tiene como principio básico hacer incidir una delgado haz de electrones acelerados, con energías que van de unos cientos de eV hasta una decena de $\mathrm{KeV}$ (un eV es la energía asociada con un cambio de un voltio en el potencial de un electrón), sobre una muestra gruesa, opaca a los electrones. Este haz se focaliza sobre la superficie de la muestra de forma que realiza un barrido de la misma siguiendo una trayectoria de líneas paralelas.

La señal emitida por los electrones y radiación resultantes del impacto se recoge mediante un detector y se amplifica para cada posición de la sonda. Las variaciones en la intensidad de la señal, que se producen conforme la sonda barre la superficie de la muestra, se utilizan para variar la intensidad de la señal en un tubo de rayos catódicos que se desplaza en sincronía con la sonda. De esta forma existe una relación directa entre la posición del haz de electrones y la fluorescencia producida en el tubo de rayos catódicos. El resultado es una imagen topográfica muy ampliada de la muestra.

Los análisis de Microsonda Electrónica se realizaron igualmente en el CAI de Microscopía Electrónica Luis Bru de la Universidad Complutense (fig. 4). En este tipo de técnica el bombardeo de electrones sobre la muestra, genera rayos $\mathrm{X}$ que son exhaustivamente

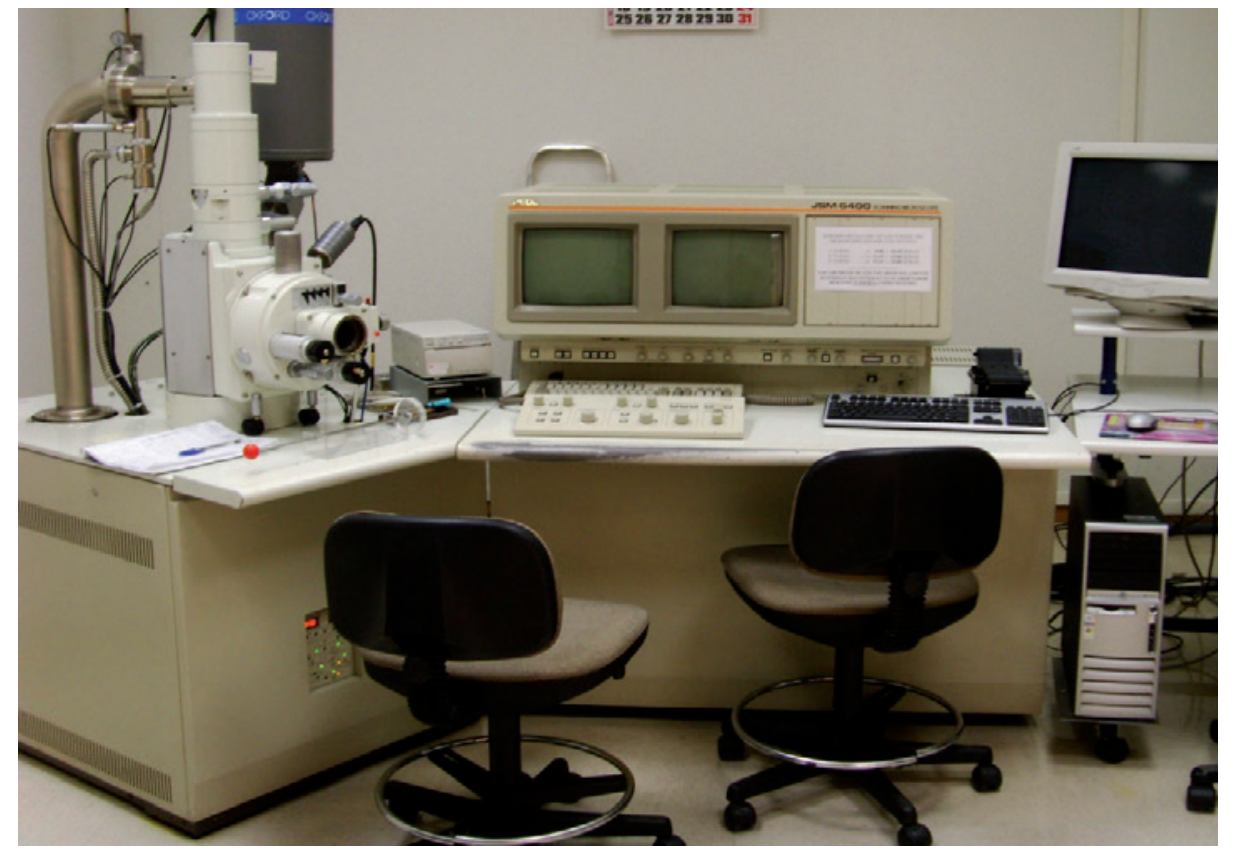

Figura 3. Microscopio Electrónico de Barrido. 


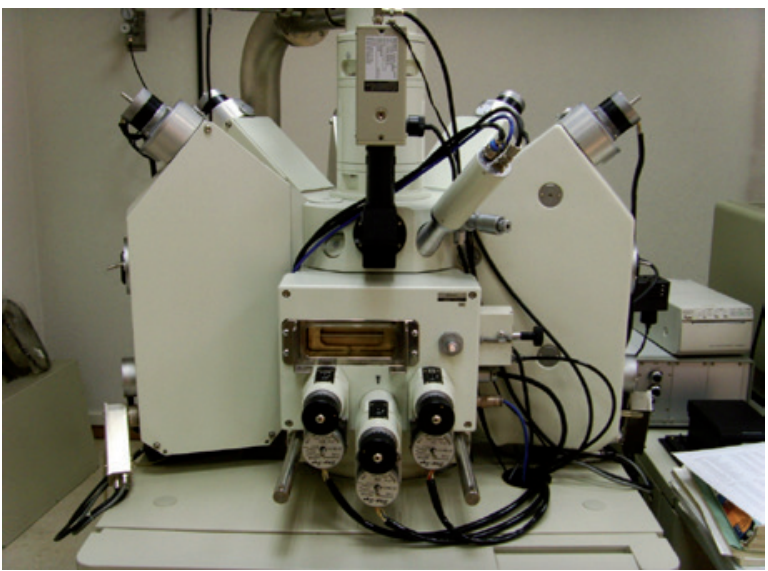

Figura 4. Microsonda Electrónica.

analizados. Así, con la longitud de onda o la intensidad de las líneas en el espectro de rayos $\mathrm{X}$, los elementos presentes pueden ser identificados y sus concentraciones estimadas. El uso de un haz de electrones muy finamente focalizado consigue seleccionar un área muy pequeña para ser analizada.

\section{RESULTADOS}

\section{Muestras arqueológicas}

\section{Pilum (Cerro Muriano, Córdoba)}

La población de Cerro Muriano se encuentra en la Sierra de Córdoba, a $16 \mathrm{~km}$ de la capital. Esta localidad cuenta con una gran abundancia de restos arqueológicos, ya que sus recursos mineros fueron explotados durante un largo período de tiempo. El complejo de Cerro Muriano está formado por varias estaciones arqueológicas situadas en un gran cerro (Cerro de la Coja), y se mantiene en buenas condiciones de conservación al hallarse dentro de unos terrenos en propiedad del Ejército Español.

Cerro Muriano es un magnífico ejemplo para el estudio de la Metalurgia, tanto por proporcionar datos valiosos de su origen como de su desarrollo, ya que cuenta con restos de escorias, lingotes y herramientas de trabajo minero y metalúrgico desde sus orígenes prerromanos hasta principios del siglo XX. El conjunto minero de Cerro Muriano posee una de las secuencias estratigráficas arqueológicas más completas de toda la Península Ibérica en este tipo de yacimientos destinados a la extracción, explotación del mineral y a la obtención y manufactura del metal en lingotes o piezas acabadas. En el mismo, se han recuperado restos que abarcan desde el Calcolítico, hasta su abandono definitivo hacia el año 1929, cuando la Copper Córdoba Company decide desistir de los recursos que ofrecía el yacimiento, por lo que se encuentran elementos de interés que abarcan unos cinco mil años de antigüedad.

Es durante los periodos Republicano y Altoimperial romanos (Siglos I a.C. al I d.C.), cuando la explotación minera se hace más intensa y sistemática, configurando el yacimiento, en su conjunto, un autentico distrito minero solo equiparable a las famosas zonas arqueológicas que se han excavado en el sur de Portugal (Alemtejo), o en la provincia de León (Las Médulas).

La pieza objeto de estudio, un pilum ibérico (siglos III-II a. C.), fue cedida por el Museo del Cobre de Cerro Muriano (Córdoba) para su análisis. Se trata de una pieza rescatada de un yacimiento ibérico que fue anegado por el pantano del río Guadamuño. El estado de conservación es bueno, manteniendo todavía una pátina de magnetita en la punta (fig. 5).

En esta pieza se aprecia, mediante la observación con Microscopia Óptica Convencional, una estructura de granos de ferrita con morfologías equiaxiales (fig.6). A través del Microscopio Electrónico de Barrido se puede que los carburos de hierro precipitados son, en su totalidad, cristales aciculares (fig. 7).

El tamaño encontrado es muy homogéneo (entre 5 y $10 \mu \mathrm{m}$ ), así como su distribución dentro de los granos ferríticos. No se aprecia la ausencia de carburos junto al límite de grano, pero sí se observa que éste, en numerosas ocasiones, está enteramente formado por cementita continua. Estos carburos se disponen orientados en estructura Widmanstätten unos con respecto a otros, de manera bastante evidente. Se aprecia que ciertos carburos llegan a tocar, e incluso atravesar, algún límite de grano, cambiando en orientación a los planos preferentes de ambos granos.

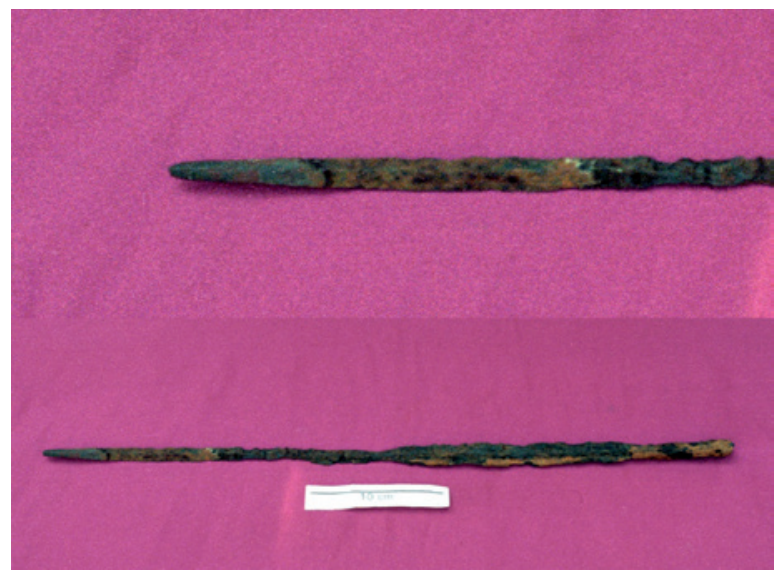

Figura 5. Pilum ibérico. 


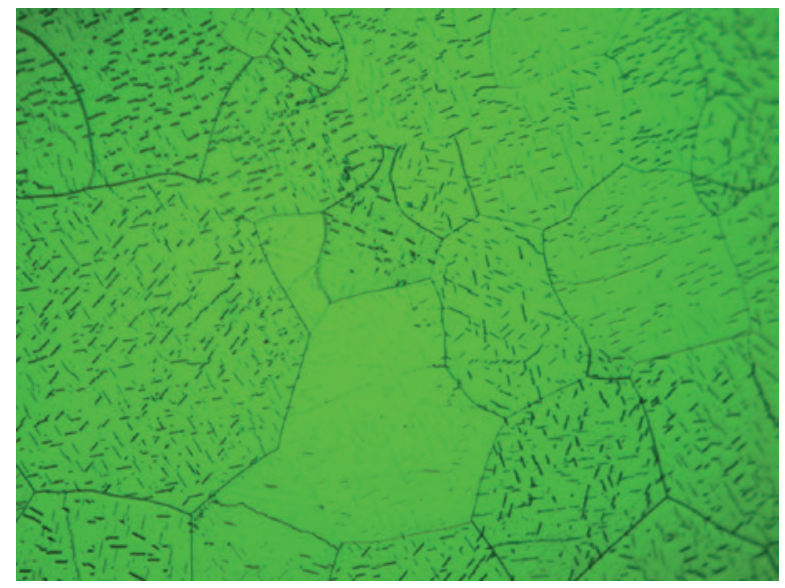

Figura 6. Imagen del Microscopio Óptico mediante campo claro con filtro verde.

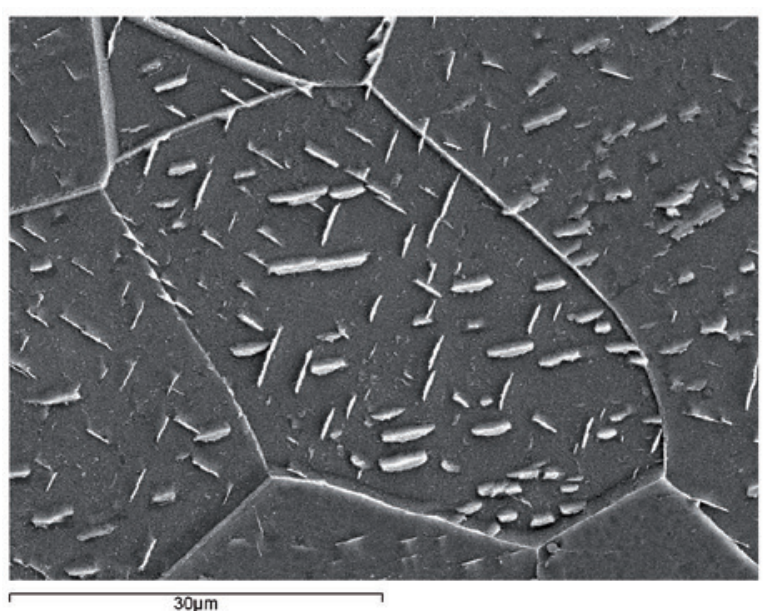

Figura 7. Imagen mediante Microscopía Electrónica de Barrido.
Para comprobar la composición de estos precipitados, se realizó un análisis en Microsonda Electrónica. Con éste se pretendía hacer una serie de medidas de composición entre dos puntos de la muestra. Como se observa en la fig. 8, la Microsonda Electrónica sólo detecta dos componentes en la línea de análisis, el Carbono y el Hierro. Los picos de aumento de concentración de carbono asociado al decremento de concentración de hierro, coinciden con la imagen de los precipitados. Por tanto este análisis confirma que la composición de los precipitados es de cristales de cementita (carburo de hierro) y descarta la presencia de nitrógeno.

Falcata del Museo Armería de Vitoria-Gasteiz.

Se trata de una falcata ibérica cedida por el Museo Armería de Vitoria Gasteiz, cuya datación es del siglo V al II a. C. Su estado de conservación es bueno y la muestra se tomó de la punta de la misma (fig. 9).

En una primera aproximación, mediante Microscopia Óptica Convencional, son observables los granos de ferrita en el núcleo metálico de la muestra, con una capa de magnetita en la superficie (fig. 10). Mediante Microscopia Electrónica de Barrido, se pueden apreciar los granos ferríticos y los precipitados de cementita, con forma acicular, en el interior. Los granos de ferrita presentan una forma equiaxial, aunque su tamaño no es homogéneo debido a procesos de recristalización. (Fig. 11). La orientación de los precipitados de carburo de hierro dentro del grano ferrítico es, la correspondiente a la estructura Widmanstätten, homogéneamente repartidos y con gran similitud en sus tamaños y morfología, siendo el tamaño medio de $5 \mu \mathrm{m}$. Existen algunos granos en los que
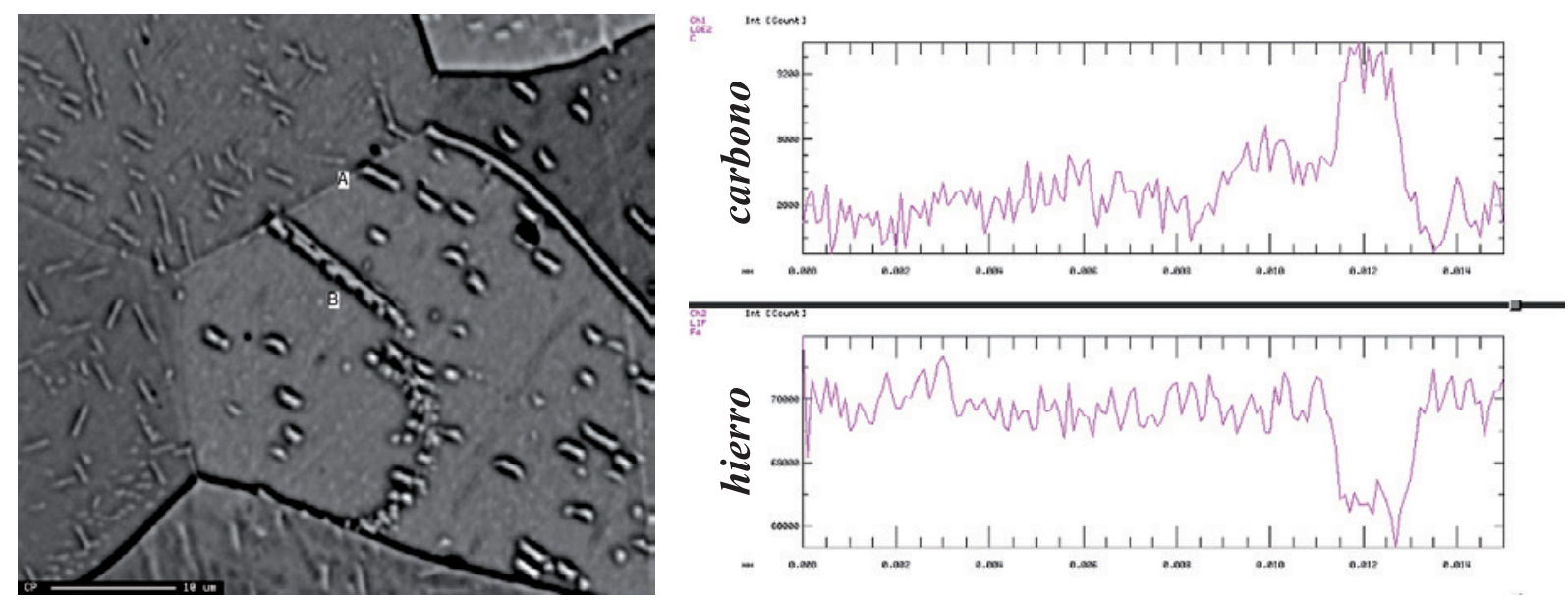

Figura 8. Gráfica del análisis con Microsonda Electrónica. 
Figura 9. Falcata cedida por el Museo Armería de Vitoria-Gasteiz.

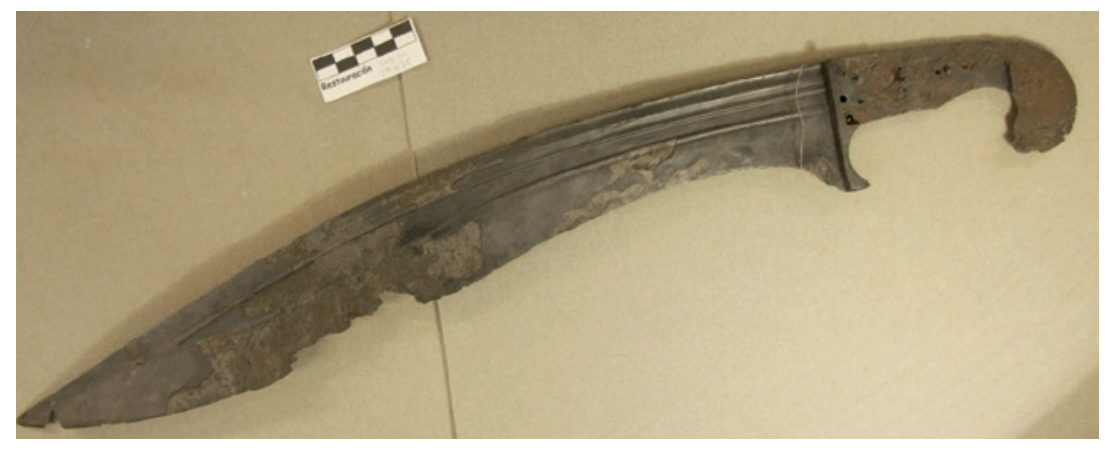

apenas ha empezado el crecimiento de los precipitados aciculares de carburo de hierro, mientras que en otros son de mayor tamaño y se ven más claramente.

Para comprobar la composición de los precipitados en forma de agujas se realizaron, al igual que

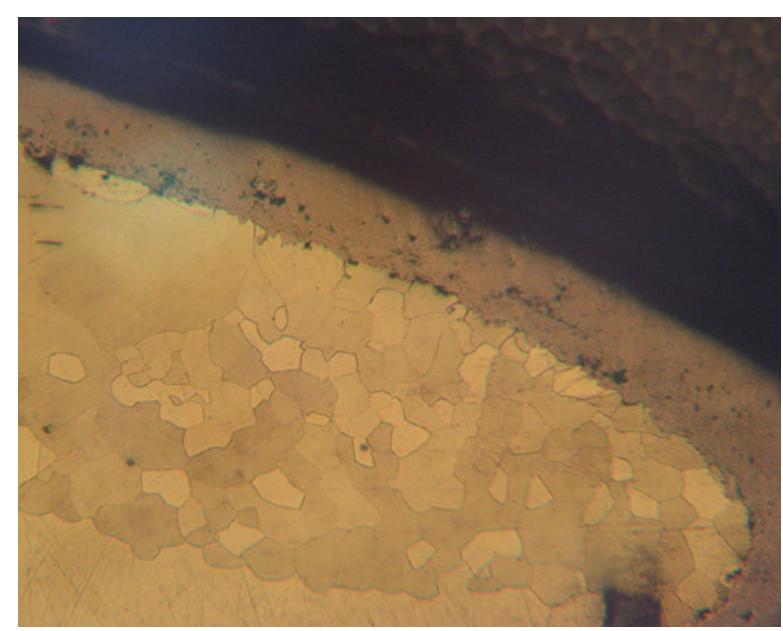

Figura 10. Imagen mediante Microscopio Óptico. en la muestra del pilum, dos análisis en Microsonda Electrónica. Recordar que con estos análisis se hacen una serie de medidas de composición entre dos puntos de la muestra (fig. 12). Se observa en el análisis con esta técnica como los cristales de carburo

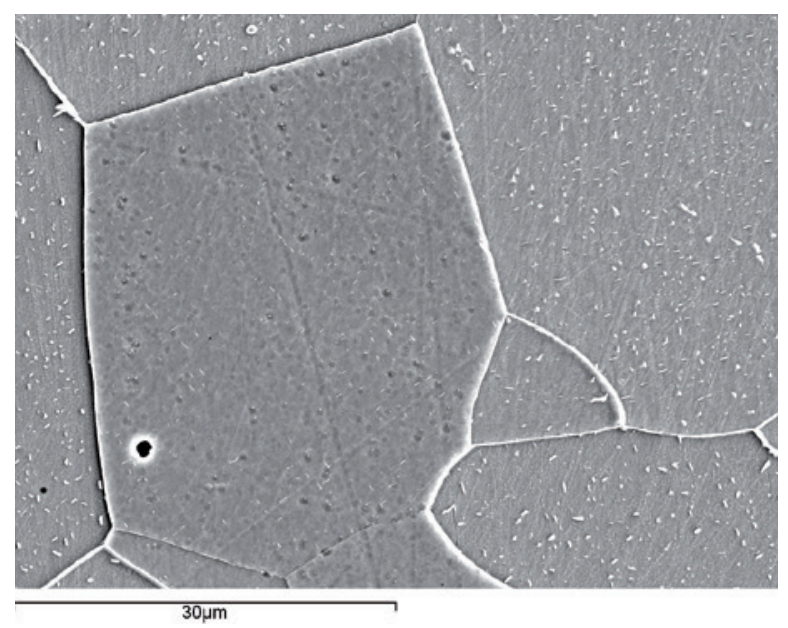

Figura 11. Imagen mediante Microscopía Electrónica de Barrido.
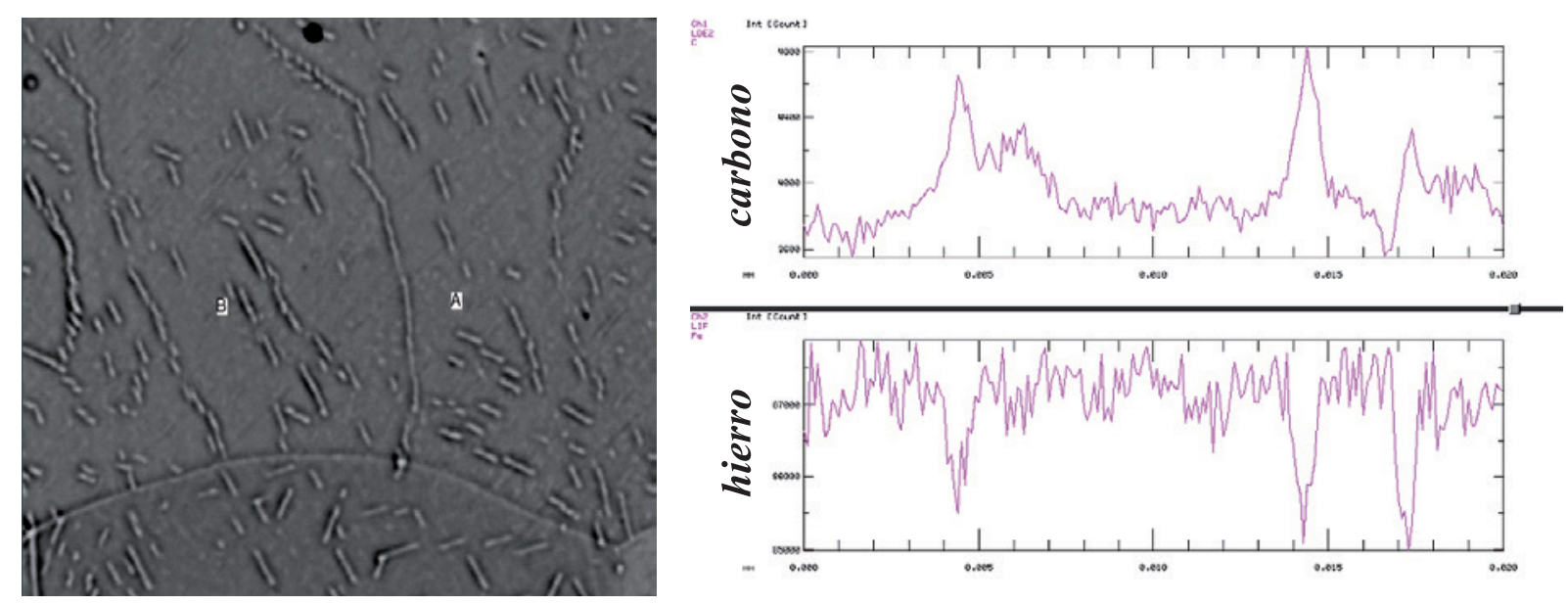

Figura 12. Gráfica del análisis con Microsonda Electrónica. 


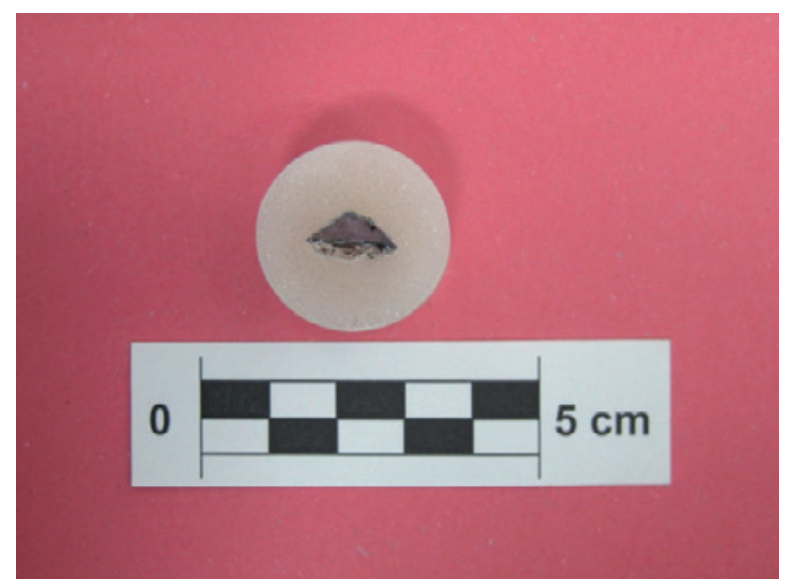

Figura 13. Muestra embutida de la tachuela.

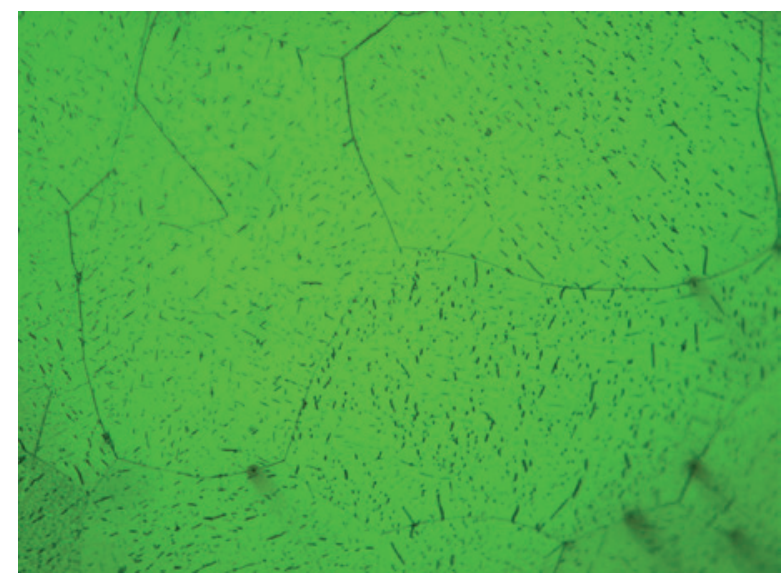

Figura 14. Imagen del Microscopio Óptico mediante campo claro con filtro verde.

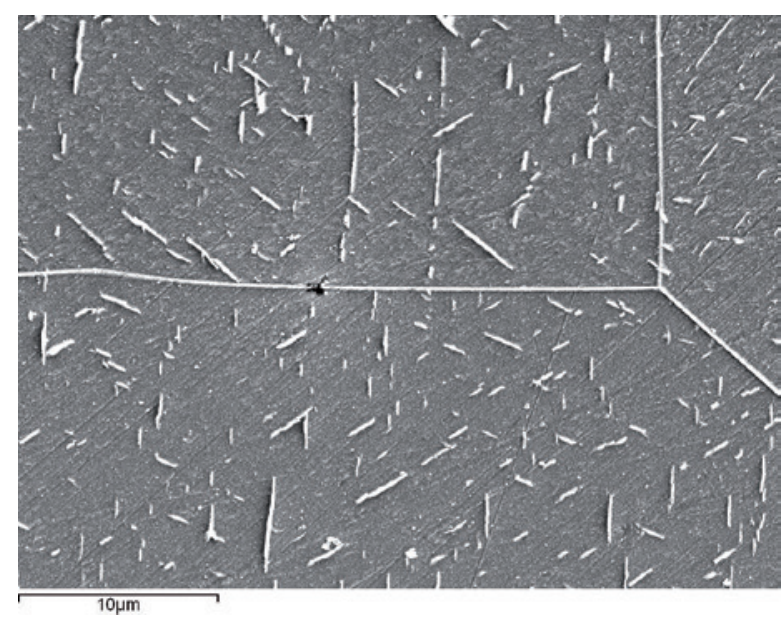

Figura 15. Imagen mediante Microscopía Electrónica de Barrido. de hierro, con estructura Widmanstätten, contienen carbono y hierro, según el perfil analítico, descartando la posibilidad de que sean nitruros de hierro.

Tachuela (Villanueva de Teba, Burgos).

El yacimiento arqueológico de Villanueva de Teba, en Burgos, se encuentra situado en las estribaciones del sistema Cantábrico en su vertiente sur. Se trata de una necrópolis con enterramientos de cremación. La cronología del yacimiento se estima entre s. IV-III a. C. Los pobladores de las tierras se corresponden a culturas prerromanas de la Edad del Hierro II, de tradición de Campos de Urnas Tardíos (Grupo Miraveche - Monte-Bernorio) con escaso influjo celtibérico.

En esta necrópolis se halló la tachuela objeto de estudio en muy buen estado de conservación. Una vez preparada la probeta (fig. 13), se observó la muestra mediante Microscopia Óptica Convencional y Microscopia Electrónica de Barrido.

Mediante Microscopia Óptica Convencional se puede observar en esta pieza la aparición de precipitados de cristales de cementita con la morfología acicular típica de las muestras arqueológicas incineradas. Se usó también el filtro verde para resaltar aún más las agujas de cementita dentro del grano ferrítico (fig. 14).

En Microscopia Electrónica de Barrido se evidencia que los granos de ferrita presentan una forma equiaxial en la que, en general, los puntos triples de unión de tres granos se aproximan a los $120^{\circ}$ del cristal metálico ideal (fig. 15). La orientación de los cristales de cementita dentro del grano ferrítico es la correspondiente a la estructura Widmanstätten, homogéneamente repartidos y con una alta similitud en tamaño y morfología, siendo su tamaño medio en torno a las $5 \mu \mathrm{m}$; exceptuando algunas zonas en plena evolución a aumento y disminución de tamaño. En numerosos casos el límite de grano presenta cementita continua y no se aprecia que la zona adyacente muestre un empobrecimiento en precipitados de carburo de hierro. Se llegan a observar carburos de hierro atravesando el límite de grano, aunque respetando las diferentes orientaciones de cada uno. En la morfología de los cristales se aprecian planos rectos, dejando evidencia de la estructura cristalina de los carburos de hierro precipitados en el interior de los granos. 
Hebilla de placas de defensa

(Villanueva de Teba, Burgos).

Esta pieza, una hebilla de placa de defensa, también pertenece a la necrópolis de cremación de Villanueva de Teba (Burgos) y datada, como se ha apuntado anteriormente, entre los siglos IV y III a. C. Su estado de conservación es bueno, manteniendo fosilizado parte del cuero (fig. 16).

En esta pieza se evidencia, ya en el Microscopio Óptico, como las microestructuras reveladoras de la materia objeto de estudio se encuentran en la zona del núcleo y no en las zonas de la superficie, volviéndose a utilizar el filtro verde para resaltar la morfología del interior de la muestra (fig. 17). Se puede observar la aparición de precipitados de carburo de hierro en el interior del grano ferrítico de forma evidente, con sus morfologías aciculares en estructura Widmanstätten, típicas de piezas de acero arqueológicas incineradas.

Los carburos de hierro, en la matriz ferrítica, se revelan perfectamente en Microscopia Electrónica de Barrido. Son bastante homogéneos en su tamaño y distribución; así como, es muy evidente, su distribución regular en estructura Widmanstätten (fig. 18). La orientación de los cristales de cementita dentro del grano ferrítico presentan una clarísima estructura Widmanstätten, presentando cristales de carburo de hierro, homogéneamente repartidos y con una alta similitud en tamaño y distribución, siendo su tamaño medio en torno a las $5 \mu \mathrm{m}$.

\section{Muestras experimentales}

El tratamiento al que se ha sometido el acero experimental AISI 1005 ha sido un calentamiento hasta campo austenítico $\left(1000^{\circ} \mathrm{C}\right.$ durante una hora) y posterior enfriamiento al aire. Debido al cambio de temperatura, la fase austenita deja de ser estable ya que las fases estables a menor temperatura son las de ferrita y cementita. La fase ferrita, pobre en carbono, necesita segregar el anteriormente disuelto. Esta segregación del carbono se produce mediante la precipitación de la fase cementita (rica en carbono), de forma que se produce un crecimiento conjunto de láminas alternadas de ferrita y cementita, formándose una estructura característica de las transformaciones eutécticas, que en el acero se conoce como perlita. La perlita forma láminas porque los átomos de carbono necesitan difundir la distancia mínima dentro de esta estructura.

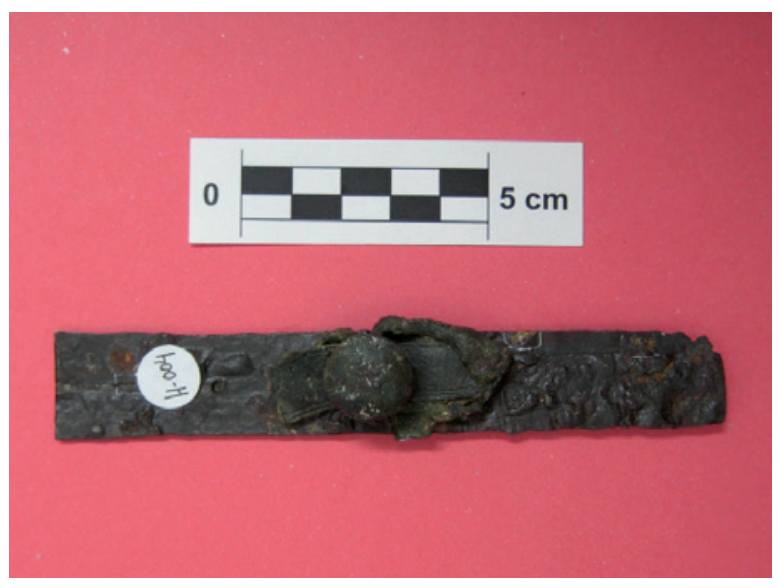

Figura 16. Hebilla de placas de defensa

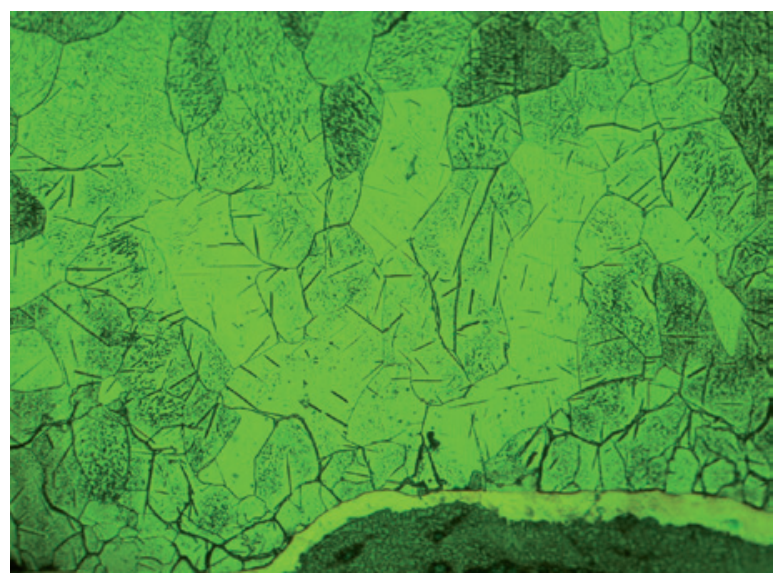

Figura 17. Imagen con Microscopio Óptico mediante campo claro con filtro verde.

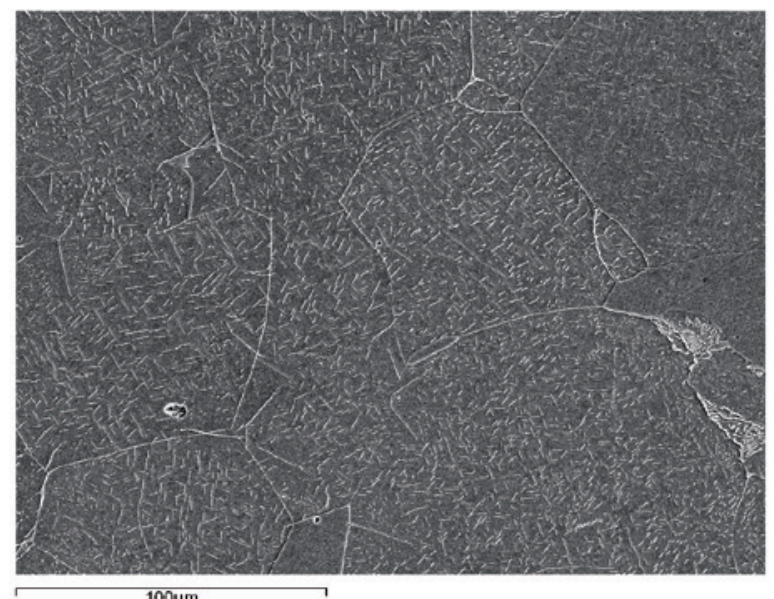

Figura 18. Imagen mediante Microscopía Electrónica de Barrido. 


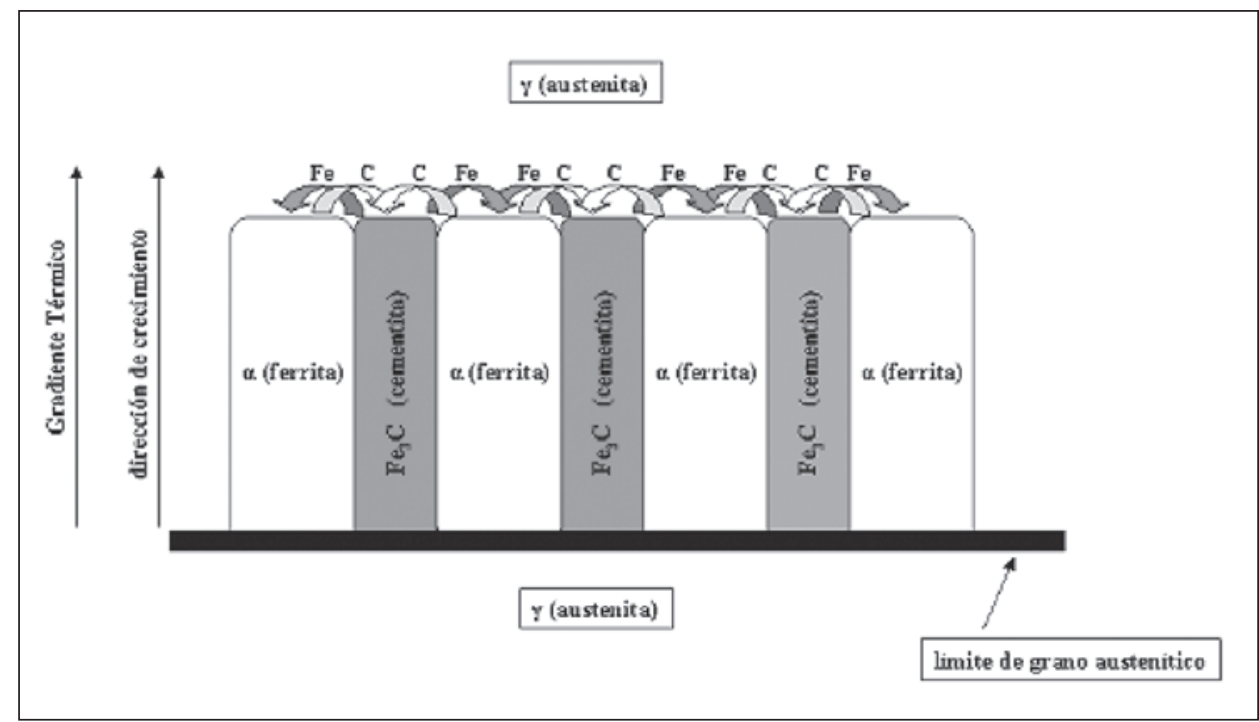

Figura 19. Esquema de formación del eutectoide $\mathrm{Fe}-\mathrm{C}$ con crecimiento cooperativo de ambas fases.

La fig. 19 ilustra esquemáticamente los cambios microestructurales que acompañan la reacción eutectoide de formación de perlita (las flechas indican la dirección de la difusión del carbono). El crecimiento se produce a partir del límite de grano debido a factores energéticos, ya que la nucleación es más fácil en zonas de mayor energía (como superficies, dislocaciones o límites de grano). Los átomos de carbono difunden de la región ferrítica a las capas de cementita para conseguir la concentración del $6,70 \%$ en peso de $\mathrm{C}$ y la perlita se propaga a partir de los límites de grano al interior de los granos austeníticos.

En las probetas tratadas se ha empleado como reactivo de ataque Nital al 4\%, el cual incide en las zonas de ferrita con más alto contenido energético, evidenciando de esta manera las formaciones claramente y revelando

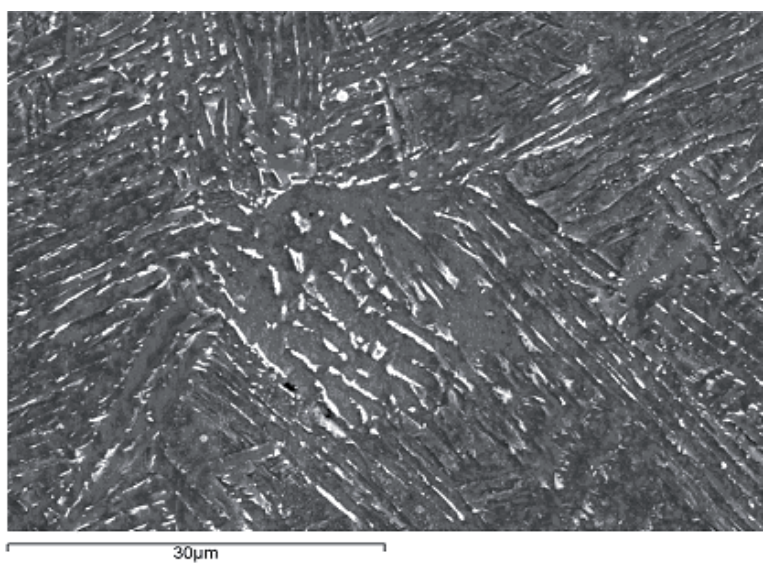

Figura 20. Muestra experimental después de 948 horas y tomada mediante Microscopía Electrónica de Barrido. estructuras como la de la perlita y el límite de grano. A partir del material normalizado se realizó un tratamiento térmico de revenido, a una temperatura moderada y un posterior enfriamiento lento en el horno. Este tratamiento se realizó, como se ha expuesto en la técnica experimental, en ampollas de vidrio. El revenido se realizó a una temperatura de $300^{\circ} \mathrm{C}$, con unos períodos de tiempo que van desde unas horas a 10000 horas.

Las estructuras que se observan con los revenidos a $300{ }^{\circ} \mathrm{C}$, entre unas horas y 10000 horas, van mostrando la aparición de carburos de hierro en las interfases de las agujas de ferrita. Así, a 948 horas, ya se observa claramente esta precipitación de carburos, a lo largo de las interfases de ferrita, alineados y orientados en estructura Widmanstätten (fig. 20). El envejecimiento ya se nota de manera efectiva, pero incluso con menos tiempo podemos sorprender la nucleación de numerosos carburos a lo largo de las interfases de ferrita acicular.

Ya a partir de las 1416 horas de calentamiento a $300^{\circ} \mathrm{C}$ las imágenes que se aprecian se parecen mucho a las observadas en las muestras arqueológicas estudiadas. A continuación presentamos una secuencia de la evolución de estos precipitados de carburo de hierro, en relación al tiempo de calentamiento transcurrido, comparándola con la estructura de la hebilla y de la falcata. Las imágenes han sido obtenidas mediante Microscopía Electrónica de Barrido, jugando con el brillo y el contraste de la imagen suministrada por los electrones secundarios. En los distintos ángulos de las micrografías aparece la imagen original y ocupando el resto de la superficie la imagen, contrastando sólo los carburos de hierro (fig. 21-25). 


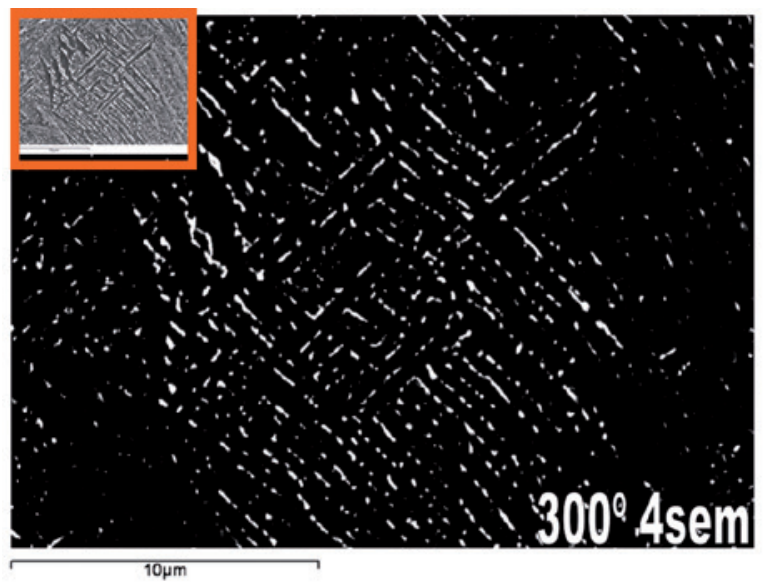

Figura 21. Muestra experimental después de cuatro semanas, tomada mediante Microscopía Electrónica de Barrido.

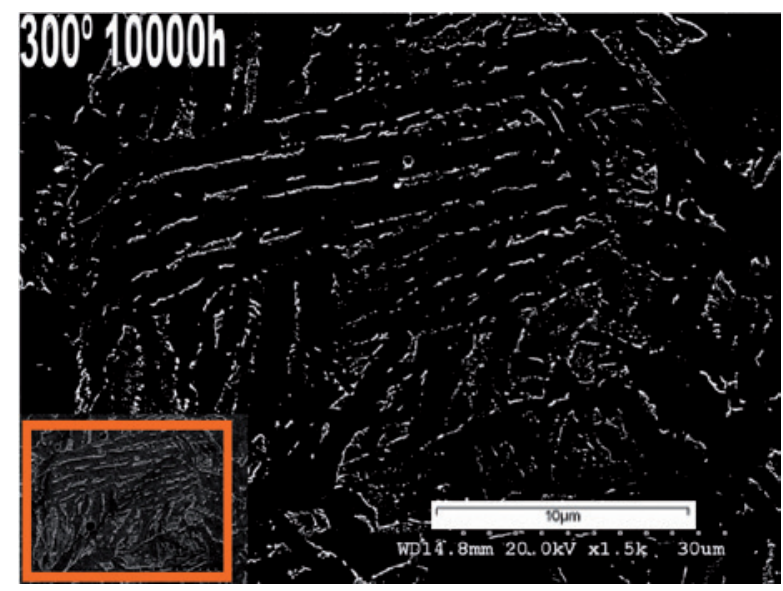

Figura 23. Muestra experimental después de 10000 horas, tomada mediante Microscopía Electrónica de Barrido.

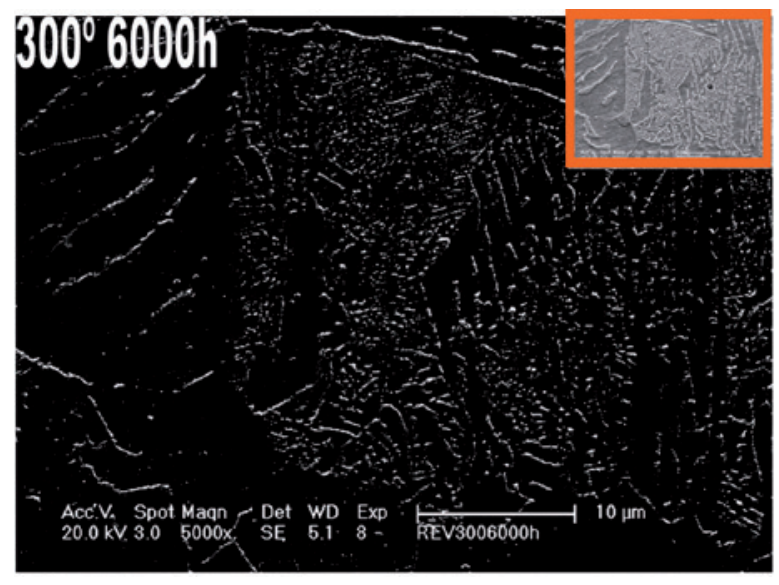

Figura 22. Muestra experimental después de 6000 horas, tomada mediante Microscopía Electrónica de Barrido.

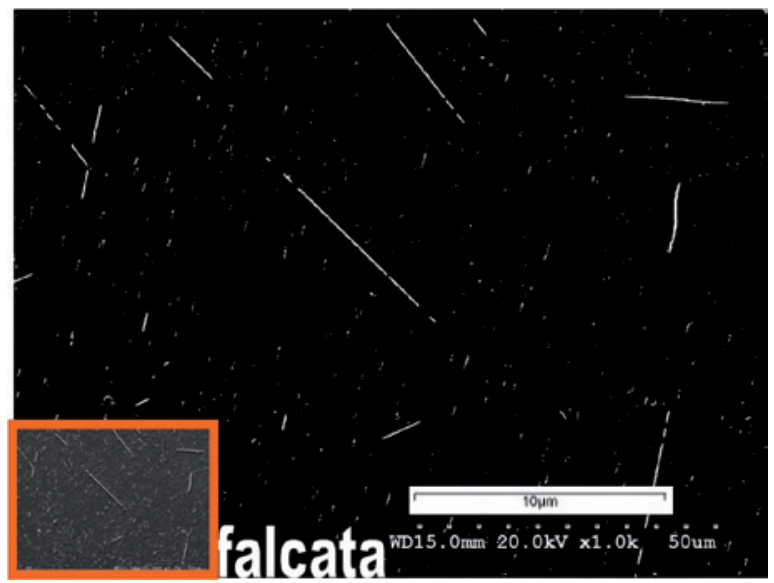

Figura 24. Imagen de la falcata tomada mediante Microscopía Electrónica de Barrido.

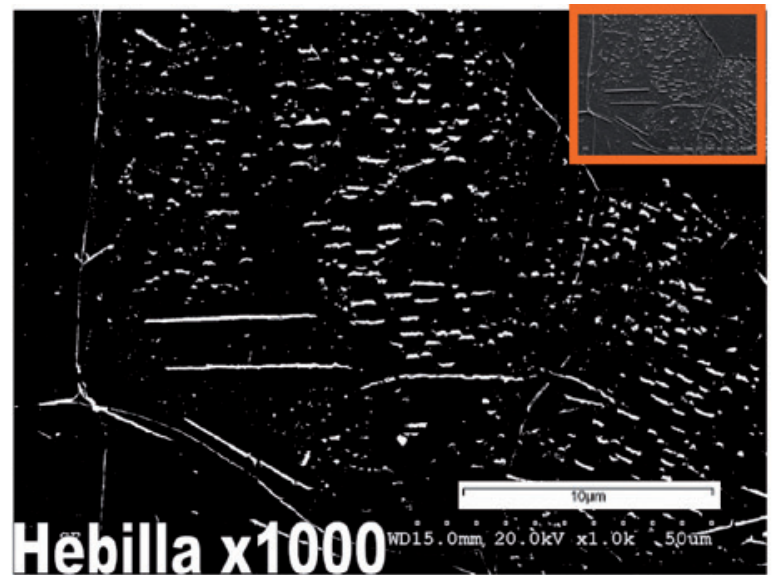

Figura 25. Imagen de la hebilla, tomada mediante Microscopía Electrónica de Barrido. 


\section{Cuantificación de la nucleación y crecimiento de los carburos de hierro en la matriz ferrítica}

Tratamiento térmico inicial

El acero AISI 1005 fue recocido a $1000^{\circ} \mathrm{C}$ durante 1 hora y, posteriormente, enfriado al aire. El tratamiento de envejecimiento natural de las piezas arqueológicas ha sido simulado, provocando calentamientos prolongados a $300^{\circ} \mathrm{C}$ y tiempos de entre unas horas y 10000 horas, para acelerar el proceso.

\section{Nucleación}

El segundo paso consiste en el tratamiento de envejecimiento simulado o revenido, en el cual, mediante el tratamiento térmico a $300^{\circ} \mathrm{C}$, favoreceremos la difusión de átomos de carbono para la formación de los núcleos de los carburos. A las 24 horas ya se observa una cantidad apreciable de pequeños carburos (en un área de 10 micras cuadradas, 40 núcleos) de un tamaño medio de 0.25 micras. $\mathrm{Su}$ forma es esférica y aparece el precipitado entre las agujas de ferrita metaestable, en especial asociadas al límite de grano. Este hecho se debe a que la nucleación es preferente en las zonas de más desorden atómico, o alta energía.

La fig. 26 muestra la evolución del número de núcleos encontrados en un área de 10 micras cuadradas. Se aprecia que el valor máximo es a las 4 semanas, el cual decae hasta valores muy bajos, 8 o 9 núcleos trascurridas más de 47 semanas.

\begin{tabular}{|c|c|}
\hline Semanas & $\mathrm{N}^{\circ}$ núcleos \\
\hline 0,14 & 40 \\
\hline 1 & 37 \\
\hline 4 & 97 \\
\hline 7 & 55 \\
\hline 35 & 13 \\
\hline 47 & 9 \\
\hline 59 & 8 \\
\hline
\end{tabular}

Figura 26

\section{Crecimiento}

El tercer paso del modelo consiste en aportar un número suficiente de horas a baja temperatura para que se produzca la segregación y difusión de todo el carbono retenido hasta alcanzar la estabilidad energética. Esto dará lugar al crecimiento de los núcleos de carburos generados en el segundo paso, los cuales crecen en las posiciones situadas entre las agujas de ferrita producidas en el proceso de normalizado.

Se aprecia en las probetas de 7, 35, 47 y 59 semanas como el tamaño de los carburos crece progresivamente en forma acicular o alargada, alineándose los núcleos entre sí para acabar dando lugar a las citadas agujas. Este es un proceso normal de crecimiento, en el cual es más favorable que las partículas pequeñas, con una mayor inestabilidad energética (gran superficie por unidad de volumen), se disuelvan y se produzca una migración atómica hacia las grandes, debido a que así se reduce la energía de la interfase precipitado-matriz (fig. 27). Este hecho fuerza a que a medida que crecen las agujas de cementita, decrece el número de núcleos. En las piezas arqueológicas y en las últimas etapas de la simulación se observa la ausencia de carburos pequeños en las inmediaciones de las agujas de mayor tamaño. Este hecho está en buena relación con el modelo de crecimiento propuesto.

\section{DISCUSIÓN GENERAL DE RESULTADOS.}

De la observación de las muestras estudiadas y de los estudios que se derivan de la literatura internacional relacionada con el mundo de los aceros incinerados, se puede asegurar que la aparición de carburos de hierro idiomórficos con estructura Widmanstätten, en granos de ferrita, son un vector afirmativo de la incineración de esas piezas de acero con el cadáver. Además, se puede afirmar, que es general, ya que otras piezas de acero que han sufrido niveles de incendio solo presentan cementita globulizada en las colonias perlíticas, pero nunca los carburos idiomórficos con estructura Widmanstätten.

La naturaleza de estos carburos ha sido puesta en cuestión algunas veces por autores que aseguran que se trata de nitruros de hierro idiomórficos. Pero estos autores nuca han hecho un estudio analítico de ellos para comprobar su hipótesis. Por el contrario, todos aquellos que los han analizado, han llegado a la misma conclusión que nosotros. En nuestro caso, hemos utilizado la Microsonda Electrónica, que los ha identificado con seguridad como carburos de hierro, sin detectar en ningún lugar la presencia de nitrógeno, procedente de la combustión de los tejidos humanos.

La nitruración es un proceso industrial de gran importancia en la actualidad, sobre todo para nitrurar 


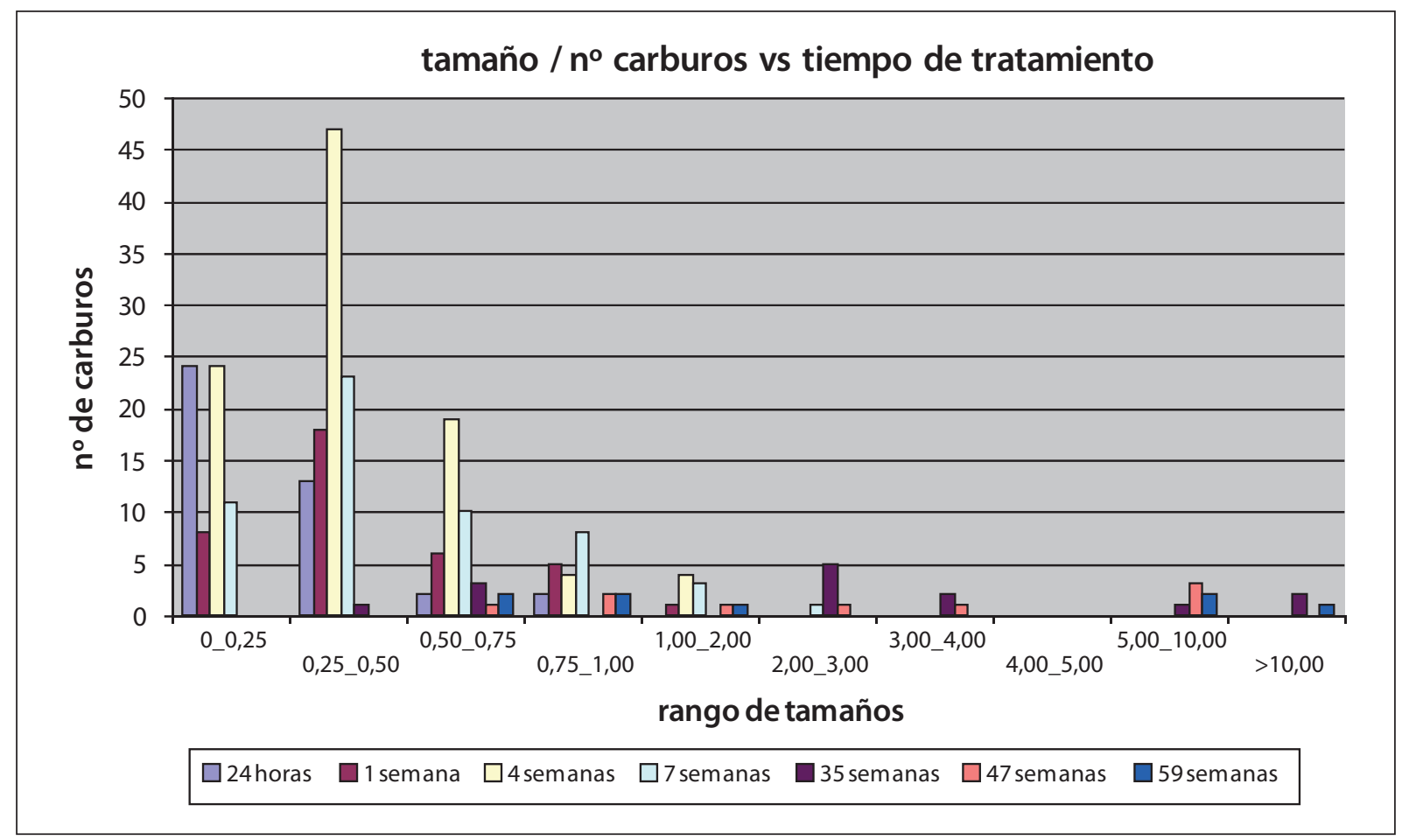

Figura 27. Gráfica global en la que se compara el número de núcleos de carburos, su tamaño y el tiempo de tratamiento.

piezas que deben resistir el desgaste: aceros de herramientas, ejes de motores, rodamientos, piñones de transmisión, etc. La máxima profundidad de capa de nitruración suele rondar los $0,2 \mathrm{~mm}$. Hay que pensar que para que el nitrógeno alcance una profundidad de 0,6 $\mathrm{mm}$, se necesitan 60 horas de tratamiento a temperaturas elevadas. Queda por tanto muy lejos de los hechos observados en las piezas arqueológicas.

Mediante el estudio de simulación se ha podido conocer que las temperaturas que estos aceros deben sobrepasar, en su calentamiento, para obtener una estructura de ferrita acicular evidente, son $\operatorname{los} 950^{\circ} \mathrm{C}$, pudiéndose alcanzar y superar los $1000^{\circ} \mathrm{C}$. Esta estructura, en los aceros al carbono actuales, se produce en bruto de colada (Lide 2004: 1443-1444). Osea, durante el enfriamiento de los lingotes de acero, que naturalmente provienen del acero en estado líquido a la salida del horno o del convertidor. La siguiente operación que se hace a estos lingotes es un desbaste por forja y laminación.

Estas temperaturas propuestas por nosotros, tras nuestra investigación, no difieren de muchas de las propuestas por la literatura internacional, que basa sus afirmaciones, básicamente, en la cristalinidad y/o color de los huesos o por el color de las cerámicas. Por tanto, nuestra investigación corrobora estos datos, quizás con una ligera tendencia al alza, ya que las piezas metálicas son más conductoras del calor y adquieren éste con mayor facilidad.

Hay estudios rigurosos que han abordado el tema de la temperatura alcanzada por el cadáver, tanto en una pira funeraria como en un incendio (Wells 1960: 2937); incluso han podido estudiar el uso de huesos de animales como combustible en el Paleolítico Medio y Superior y la temperatura alcanzada en estos hogares (Yravedra 2005: 369-383). Así mismo, algunos autores han publicado, en la literatura internacional, experiencias sobre simulaciones con piras funerarias reales y han medido, mediante termopares, las temperaturas alcanzadas (McKinley 1997: 129-145).

De estos trabajos y de nuestras experiencias en laboratorio, se deduce, que la temperatura alcanzada por el cadáver en su combustión, es menor que en otros lugares de la pira o en materiales suntuarios que acompañaban a dicho cadáver. Incluso no todas las partes del cuerpo humano alcanzan la misma temperatura, ya que hay partes de éste que son plenamente combustibles, como las grasas y los elementos óseos esponjosos, epifisiarios y axiales. Los huesos retardan la combustión de la leña y bajan la temperatura alcanzada. En cambio, podemos afirmar, rotundamente, que los objetos de 


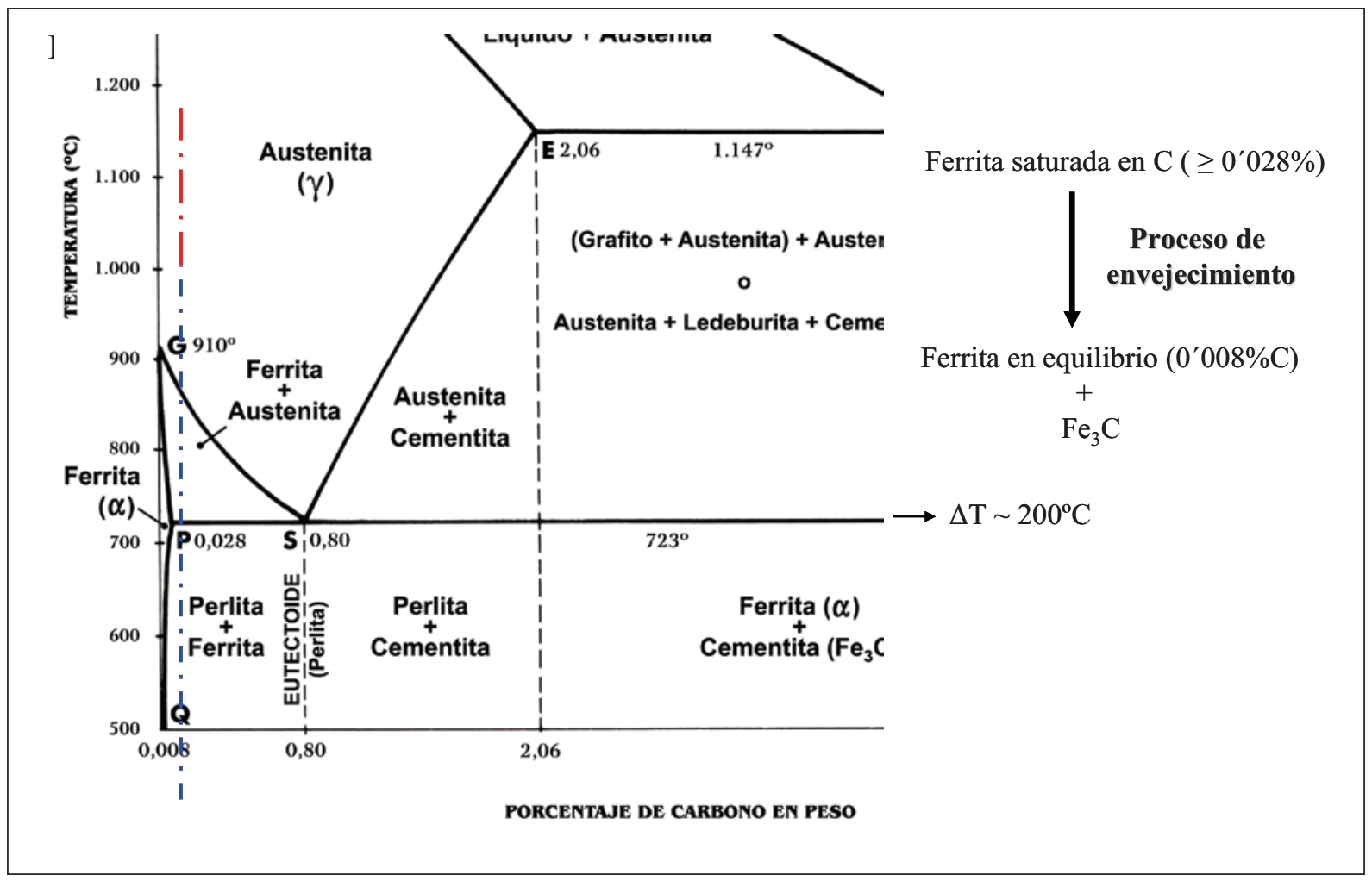

Figura 28. Diagrama de fases Fe-C de Criado.

ajuar metálicos, son los que alcanzan la máxima temperatura producida en la pira funeraria. Esto quiere decir, que el auténtico testigo de la temperatura de la pira funeraria, la marcan los elementos metálicos más conductores y, no los huesos calcinados, como hemos señalado anteriormente.

Es necesario también dejar claro, que el poder calorífico de muchas maderas es muy elevado, sobre todo de aquellas que son duras, compactas y resinosas, como: carpe, arce, roble, haya, pino, que superan en poder calorífico a la turba. Se han encontrado bronces de bajo contenido en estaño, que estaban fundidos después de la cremación, lo que nos viene a decir que se superaron los $1000^{\circ} \mathrm{C}$. Esto se observa claramente en varias piezas de la necrópolis de La Hoya (ALONSO 1999: 38-81). La consecuencia es que las piras realizadas con este tipo de maderas, podían alcanzar temperaturas muy superiores a los $1000^{\circ} \mathrm{C}$, lo que estaría en concordancia con las adecuadas para obtener los vectores metalúrgicos de la investigación, como son los carburos de hierro idiomórficos precipitados en ferrita con estructura Widmanstätten.

Para que se produzca la ferrita acicular con estructura Windmanstätten, a partir de la austenita original, el grado de subenfriamiento debe ser muy elevado, y esto sólo se consigue si el enfriamiento se realiza desde una temperatura muy elevada como en los aceros en bruto de colada (Asm Metals Handbook 2004: 1443-1444), o bien, templando, es decir, si la pira se apaga con agua o cualquier otro líquido Para ello recurrimos de nuevo al diagrama de fases Fe-C de Criado (Criado 2008: 8) (fig. 28).

En todo caso la ferrita queda saturada en carbono. Ténganse en cuenta que a temperatura ambiente la red cúbica centrada en el cuerpo del hierro (ferrita) sólo puede retener un $0,008 \%$ de carbono en masa. Todo el carbono que sobresatura esta red la tensiona, provocando que sea segregada de ella formando carburos de hierro en los lugares más favorables para hacerlo, que son las interfases de las agujas de ferrita. Esto obliga, desde un principio, a que aparezcan alineados en ciertos planos conformando la estructura que denominamos Windmansttäten.

El idiomorfismo de estos cristales y su morfología alargada vienen obligados por ocurrir a temperatura ambiente. El carácter de compuesto intermetálico del $\mathrm{Fe}_{3} \mathrm{C}$ y que algunos planos siguen siendo semicoherentes con la matriz ferrítica, hace que esa dirección 


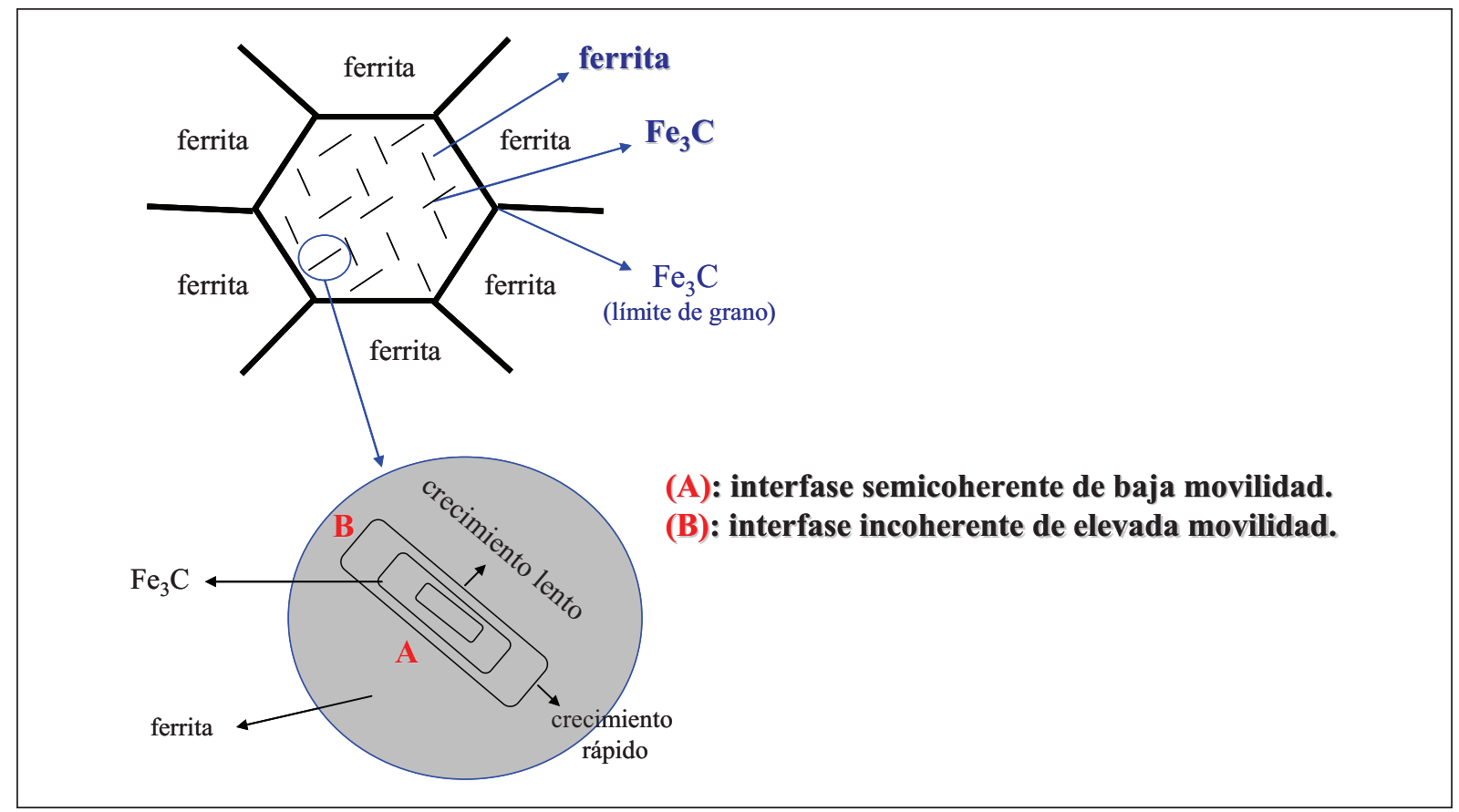

Figura 29. Proceso de precipitación de los carburos de hierro.

de crecimiento se lentifique $y$, otros, que son incoherentes con la matriz les permite crecer más deprisa, lo cual ya está estudiado por Chadwick (Chadwick 1972: 188-194) y por Porter y Easterling (Porter 1981: 279287) (fig. 29).

La velocidad de crecimiento depende del tiempo y de una constante $\mathrm{K}$, que engloba el factor difusión, la energía interfacial y la concentración en el equilibrio (fig. 30). Estos factores, a temperatura ambiente, son poco favorables, por lo que el proceso se hace muy lento y es necesario el paso de miles de años para que se complete, como hemos podido observar en las micrografías de las muestras arqueológicas.

En nuestra simulación ha sido necesario calentar a $300^{\circ} \mathrm{C}$, para favorecer esos factores que conforman $\mathrm{K}$, sobre todo el factor difusión. Pero también hemos estado muy limitados ya que temperaturas más altas, que favorecerían aún más la difusión, hubieran hecho que el idiomorfismo y cristalinidad de los carburos hubiera dejado paso a la globulización de éstos, debido a que es la morfología más estable para la cementita a altas temperaturas.

Como hemos visto en el estudio cuantitativo de tamaño y número de carburos con el tiempo, una vez formados los núcleos de carburo de hierro, comienza una competencia entre ellos. Los más grandes se desarrollan más, a costa del decrecimiento de los más pequeños, llegándose, finalmente, a un equilibrio en el que la mayoría de ellos tienen el mismo tamaño, a excepción de algunos pequeños en estado de desaparición y otros muy grandes y, por tanto, muy estables, hecho demostrado por Chadwick y Porter y Easterling.

\begin{tabular}{|l|}
\hline \multicolumn{1}{|c|}{$(\mathrm{r})^{3}-\left(\mathrm{r}_{0}\right)^{3}=\mathrm{kt}$} \\
donde $\mathrm{k}=\mathrm{D} \gamma \mathrm{x}_{\mathrm{e}}$ \\
$\overline{\mathrm{r}}:$ radio medio de las partículas de carburo de hierro \\
$\mathrm{r}_{0}:$ radio crítico de las partículas de carburo de hierro \\
$\mathrm{t}:$ tiempo transcurrido \\
$(\mathrm{r})^{3}-\left(\mathrm{r}_{0}\right)^{3}:$ aumento con el tiempo $(\mathrm{t})$ del radio $(\mathrm{r})$ de las \\
partículas; el tiempo transcurrido viene dado por \\
$\qquad \mathrm{t}=\frac{(\overline{\mathrm{r}})^{3}-\left(\mathrm{r}_{0}\right)^{3}}{\mathrm{D} \gamma \mathrm{x}_{\mathrm{e}}}$ \\
$\mathrm{D}:$ coeficiente de difusión del carbono en ferrita \\
$\gamma:$ energía interferencial entre ferrita-cementita $\left(\mathrm{Fe}_{3} \mathrm{C}\right)$ \\
$\mathrm{x}_{\mathrm{e}}:$ concentración en el equilibrio
\end{tabular}

Figura 30. Ecuación de crecimiento de las partículas de carburo de hierro.

Finalmente, hay que concluir que el proceso de simulación se podría extender más en el tiempo, 
pero existe el riesgo de la globulización ya que, aunque la temperatura de calentamiento es tan solo de $300^{\circ} \mathrm{C}$, el factor tiempo corre en contra, provocando lentamente la globulización de los cristales idiomórficos de carburo de hierro. De todos modos, tras el recuento de cristales y la valoración de sus tamaños, parece que con 10000 horas hemos llegado a valores concordantes con los observados en las piezas arqueológicas.

\section{CONCLUSIONES}

Antes de pasar definitivamente a las conclusiones cabe recordar los objetivos que se propusieron para este trabajo y que se han logrado satisfactoriamente:

- Determinar la temperatura de incineración y las velocidades de enfriamiento a las que fueron sometidas las piezas durante la cremación.

- Simular dicho tratamiento térmico en aceros modernos con el objetivo de reproducir las microestructuras encontradas.

- Conocer, una vez logrados los dos objetivos anteriores, que piezas fueron sometidas a la cremación con el cadáver y cuáles no sufrieron esta exposición al fuego y fueron depositadas, posteriormente, con el ajuar junto a la urna cineraria.

- Cuáles son los mecanismos cinéticos y termodinámicos que nos llevan a estas peculiaridades microestructurales.

Teniendo estos objetivos marcados desde un principio, las conclusiones finales son las siguientes:

1. La aparición de carburos de hierros idiomórficos con estructuras Windmanstätten, en los granos de ferrita, en las armas y otros objetos de hierro y acero de los pueblos prerromanos de la Península Ibérica, son un magnífico vector para asegurar que la pieza fue objeto de un rito de cremación.

2. La composición de dichos cristales idiomórficos, ha quedado aclarada con los análisis de Microsonda Electrónica, realizados al pilum ibérico y a la falcata, como carburos de hierro, lo que viene a confirmar otros análisis por otros métodos publicados en la literatura internacional.

3. Para que aparezcan estos cristales idiomórficos de carburo de hierro, la ferrita debe quedar sobresaturada en carbono, lo que exige un grado de subenfriamiento fuerte, que sólo se alcanza si la temperatura de cremación fue muy elevada frente a la temperatura ambiente o se usó algún líquido para apagar la pira (recordemos la importancia ritual del agua). Cuantificamos esta temperatura como de al menos $950^{\circ} \mathrm{C}$ a $1000^{\circ} \mathrm{C}$, superándose en numerosas ocasiones esta última temperatura.

4. Durante el proceso de envejecimiento natural o artificial simulado, los carburos de hierro idiomórficos, precipitan en las interfases de las agujas de ferrita, presentando, por tanto, una clara orientación en ciertos planos, originando la conocida estructura Windmanstätten.

5. Su forma idiomórfica alargada se debe a su crecimiento semicoherente en algunos planos e incoherente en otros planos.

6. Formados los núcleos cristalinos, se establece una competencia de crecimiento entre ellos, favoreciendo a los mayores y redisolviendo a los más pequeños, debido a que las energías libres son diferentes en las interfases de los cristales, provocando que la concentración en carbono de la matriz ferrítica sea diferente. Se produce un flujo de átomos de carbono de la interfase ferrita-carburo de hierro, de los más pequeños hacia los de mayor volumen.

7. La velocidad de crecimiento de los cristales viene dictada por: $\mathrm{r}^{3}-\mathrm{r}_{0}{ }^{3}=\mathrm{K} \mathrm{t}=\mathrm{D} \gamma \mathrm{x}_{\mathrm{e}} \mathrm{t}$. Para favorecer el crecimiento en los ensayos simulados hemos trabajado a $300^{\circ} \mathrm{C}$ y tiempos prolongados. Una temperatura superior a $300^{\circ} \mathrm{C}$, para los tiempos más dilatados, hubiera supuesto una segura globulización de los carburos de hierros idiomórficos formados.

En resumen y para concluir, la aparición de carburos de hierro nos están indicando tres hechos, que son los objetivos fundamentales de este trabajo y que hasta ahora en la investigación arqueológica no estaban claros: la primera es que la pieza de hierro o acero fue cremada junto al cadáver; lo segundo es que se produjo un subenfriamiento rápido de la pira, cosa que se efectuó, hipotéticamente, apagándola con algún tipo de líquido, lo que nos lleva a pensar en el agua debido a la presencia de ésta en las necrópolis y su importancia ritual; y tercero que para que se produzcan estas microestructuras típicas, la pira tuvo que llegar a una temperatura mínima de $950^{\circ}$ a $1000^{\circ} \mathrm{C}$. 


\section{BIBLIOGRAFÍA}

ALONSO, J. (1999): "Nuevas técnicas metalúrgicas en armas de la II Edad del Hierro: Arqueometalurgia y Conservación en la Necrópolis de La Hoya (Laguardia, Álava)", Arabako Foro Aldundia-Diputación Foral de Álava: 38-81.

BELÉN DEAMOS, M. (1991): La Edad del Hierro: 182-202. Síntesis, Madrid.

BLÁZQUEZ, J.M. (1976): “Arte y religión entre los íberos", Historia 16 1: 89-94.

- (1990): "La religión de los pueblos de la Hispania prerromana", I Coloquio Internacional sobre religiones prehistóricas de la Península Ibérica, Zephyrus 43: 223-233.

CHADWICK, G.A. (1972): Metallography of Phase Transformations: 188-194. The Butterwhorth Group, New York.

CRIADO, A.J. (1997): "Fabricación del acero de Damasco: estudio metalográfico", Revista de Metalurgia (CENIM), 33 (1): 44-49.

- (1999): “Origin of el Cid's sword revealed by ICP-MS metals analysis", Spectroscopy Europe 11/4: 10-14.

- (2000): "Microsstructures in historial andarchaeological steel objects resulting from aging process", Praktische Metallographie 37 (6): 370-379.

- (2000): "Metallographic study of the steel blade of the sword Tizona", Praktische Metallographie 37 (7): 315-325.

- (2000): "La espada del Cid", Investigación y Ciencia. Edición Española de Scientific American 289: 54-60.

- (2000): Análogos de los contenedores metálicos de almacenamiento. Publicación Técnica de Enresa: 26.

- (2000): Análogos arqueológicos e industriales para almacenamientos profundos: estudio de piezas arqueológicas metálicas. Publicación Técnica de Enresa: $149-160$.

- (2001): "Traditional forging of swords and knives with legitimate damascus steel", Praktische Metallographie 38 (2): 325-337.

- (2001): "Modelos para la datación de hierros y aceros antiguos aplicados a Tizona", Gladius XXI: 221-232.

- (2001): “L' epée du Cid”, Pour la Science, Edición francesa de Scientific American 280: 78-85.

- (2002): “Tres piezas metálicas descontextualizadas procedentes del complejo arqueológico de Cerro Muriano (Córdoba): relación isotópica del plomo y otros aspectos", Antiquitas 14: 9-21.
- (2003): Análogos arqueológicos e industriales para almacenamiento de residuos radiactivos: estudio de piezas arqueológicas metálicas. Publicación técnica de Enresa: 231-260.

- (2004): "A new method for datation of ancient steel simples using Vichers Microhandness", Characterization 52: 145-151.

- (2004): Aplicación de los análogos a la evaluación de seguridad y comunicación del almacenamiento geológico. Síntesis ilustrativa. Colección de documentos de I+D de Enresa y Consejo de Seguridad Nuclear 13: 107-117.

- (2004): Analoghe application to safety assessment and communication of radiactive waste geological disposal. Ilustrative Synthesis. Colección de documentos de I+D de Enresa y Consejo de Seguridad Nuclear 11: 107-115.

- (2005): Aplicación de los análogos a la evaluación de seguridad y comunicación del almacenamiento geológico. Catálogo de análogos más significativos. Colección de documentos de I+D de Enresa y Consejo de Seguridad Nuclear 13: 550-591.

- (2006): "Archaeologic analogues: microstructural changes by natural ageing in carbon steels", Journal of Nuclear Materials 349: 1-5. doi:10.1016/j. jnucmat.2005.06.022

- (2007): "A Metallographic examination of a Toledo steel sword", Praktische Metallographie 44 (4): 172-181.

- (2008): Estructuras metalográficas de aleaciones Hierro-Carbono. Parte I. Aceros al carbono. www. antoniocriado.es: 8 .

- (2009): "An archaeological analogue for a composite material of carbon steel, cooper and magnetite", Praktische Metallographie 46 (8): 377-393.

ENZO, S. (2007): “A study by termal and X-Ray Diffraction on burnt fragmented bones from tombs II, IV and IX belonging to the hypogeis necropolis of "Sa Figu" near Ittiri, Sassari (Sardinia, Italy)", Journal of Archaeological Science 37: 1731-1737. doi:10.1016/j.jas.2006.12.011

ETXEBERRÍA, F. (1987): “Agresividad social o Guerra durante el Neo-Eneolítico en la cuenca media del Valle del Ebro, a propósito de San Juan Ante Portam Latinam (Rioja Alavesa)", Munibe Antropología-Arkeología, Suplemento 6: 105-112.

FERNÁNDEZ CASTRO, M.C. (1997): La Prehistoria de la Península Ibérica. Barcelona, Historia de España, Vol. 1: 320-326. Ed. Crítica-Grijalbo Mondadori. Barcelona. 
GARCÍA HUERTA, R. (2001): Arqueología funeraria: las necrópolis de incineración: 11-169. Cuenca, Ediciones de la Universidad de Castilla-La Mancha.

GARCÍA RAYA, M.C. (1999): “Aportaciones coloniales a las creencias funerarias ibéricas”, Espacio, Tiempo y Forma, Serie II, Historia Antigua 12: 291-307.

GÓMEZ BELLARD, F. (1996): "El análisis antropológico de las cremaciones", Complutum Extra 6 (II): 55-64.

HUMMEL, S. (1988): "Advances in Cremation Research", Actes des 3émes Journees. Anthropologiques Notes et Monographies Techniques 24: 177-194.

JIMENO, A. (1993): "Ritual y dieta alimenticia: la necrópolis celtibérica de Numancia", Numantia 6: 31-44.

JORGE, J. (1987): "Christian Thomsen Jürgensen: una apreciación en el bicentenario de su nacimiento", Acta Archaeologica 58: 1-15.

LIDE, D.R. (2004): Metallography and Microestructures. Metallography and Microestructures of LowCarbon and Coated Steels. ASM METALS HANDBOOK: 1443-1444.

LIU, K.H. (1984): “Analytical electrón microscopy of early steel from Bacqah Valley Jordan”, Microbeam Analysis: 261-264.

LÓPEZ CACHERO, F.J. (2008): "Necrópolis de incineración y arquitectura funeraria en el noreste de la Península Ibérica durante el Bronce Final y la Primera Edad del Hierro", Complutum 19: 139-171.

LORRIO, A. (2005): Los celtíberos. Madrid, Biblioteca Archaeologica Hispana 25, Real Academia de la Historia, Universidad Complutense.

MCKINLEY, J.I. (1997): "Bronze Age Barrows and funerary rites and rituals of cremation", Proceedings of the prehistoric Society 63: 129-145.

MOHEN, J.P. (1992): Metalurgia Prehistórica. Introducción a la Paleometalurgia. Ed. Masson, Barcelona.
PHILIPS, W. (2005): “Time, temperature and oxygen availability: an experimental study of the effects of environmental conditions on the colour and organic content of cremated bone", American Journal of Physical Anthropology 40: 222-233.

PIASKOWSKI, J. (1961): "Metallographic investigations of ancient iron objects from the territory between the Oder and the basin of the Vistula river", Journal of the Iron and Steel Institute: 263-282.

PORTER, D.A. (1981): Phase Transformation in Metals an Alloys. Van Nostrand Reinhuld Company Ltd, London.

RUIZ, A. (1995): Los íberos. Barcelona, Ed. CríticaGrijalbo Mondadori, Barcelona.

SALINAS DE FRÍAS, M. (2006): Los pueblos prerromanos de la Península Ibérica. Akal Ediciones, Madrid.

SAN NICOLÁS PEDRAZ, M.P. (2000): Arqueología y Antropología Ibéricas: 159-166. UNED Ediciones, Madrid.

SHUGAR, A.N. (2003): "Roman Shears: Metallography, composition and a historical approach to investigation", Proccedings 1: 109-118.

VVAA (1992): Congreso de Arqueología Ibérica. Las necrópolis. Madrid, Universidad Autónoma de Madrid.

WELLS, C. (1960): “A study of Cremation", Antiquity Journal 86:133: 29.37.

WHEELER, T.S. (1980): Metallurgy and Ancient Man. The Coming of the Age of Iron: 99-126. New Haven, Editorial Theodore A. Wertime and James D. Mulhy, Yale University Press

YRAVEDRA, J. (2005): "El empleo de material óseo como combustible durante el Paleolítico Medio y Superior en el Cantábrico. Observaciones experimentales", Museo de Altamira. Monografias 20: 369-383. Santander.

FECHA DE ENTRADA: 19-10-2010

FECHA DE ACEPTACIÓN: 18-01-2011 